Portland State University

PDXScholar

\title{
Intelligibility of Speech Compared Through Two Limiter Compression Circuits
}

Lee M. Odell

Portland State University

Follow this and additional works at: https://pdxscholar.library.pdx.edu/open_access_etds

Part of the Speech and Hearing Science Commons, and the Speech Pathology and Audiology Commons

Let us know how access to this document benefits you.

\section{Recommended Citation}

Odell, Lee M., "Intelligibility of Speech Compared Through Two Limiter Compression Circuits" (1974). Dissertations and Theses. Paper 1966.

https://doi.org/10.15760/etd.1965

This Thesis is brought to you for free and open access. It has been accepted for inclusion in Dissertations and Theses by an authorized administrator of PDXScholar. Please contact us if we can make this document more accessible: pdxscholar@pdx.edu. 
AN ABSTRACT OF THE THESIS OF Lee M. Odell for the Master of Science in Speech, with emphasis in Audiology/Speech Pathology, presented February 13, 1974.

Title: Intelligibility of Speech Compared Through Two Limiter Compression Circuits.

APPROVED BY MEMBERS OF THE THESIS COMMITTEE:
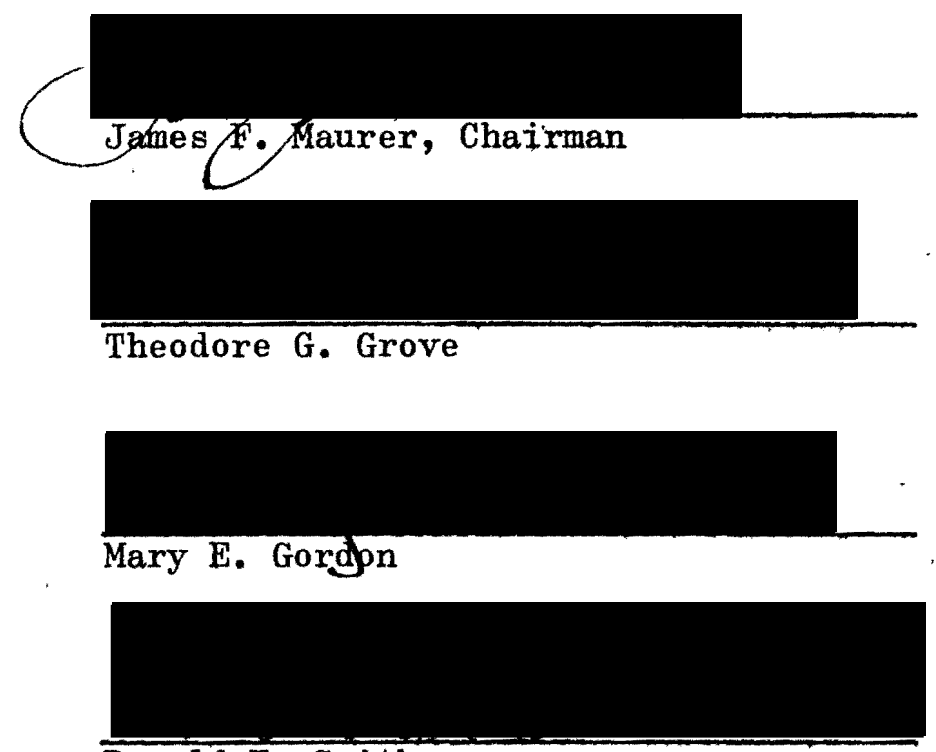

Ronald E. Smith

Hearing aid manufacturers commonly engineer automatic gain control (AGC) circuits which are aimed at reducing sound tolerance problems and improving speech intelligibility among wearers. The most common type of AGC engineered is one utilizing a fast attack time. The present study was designed to evaluate the effects of both fast and slow attack times on the intelligibility of speech. Twenty-four 
normal hearing subjects listened to sixty pre-recorded sentences through two types of hearing aid circuits. Thirty sentences were modified by a fast attack AGC circuit, and thirty sentences were modified by a slow attack AGC. The subjects marked one of four multiple-choice answers for each sentence.

The mean number of sentences answered incorrectly when heard through fast attack AGC was 8.25. When heard through slow attack AGC, the mean was 6.67 . The performance differences which exist between these two modes of signal modification suggest that the fast attack does not improve intelligibility as significantly as slow attack time among normal listeners. Further investigation into the effects of slow attack AGC circuits on the user's ability to understand speech are recommended. 
INTELLIGIBILITY OF SPEECH COMPARED THROUGH TWO

LIMITER COMPRESSION CIRCUITS

by

LEE M. ODELL

A thesis submitted in partial fulfillment of the requirements for the degree of

MASTER OF SCIENCE

IN

SPEECH

with emphasis in Speech Pathology and Audiology

Portland State University 1974 
TO THE OFFICE OF GRADUATE STUDIES AND RESEARCH:

The members of the Committee approve the thesis of Lee M. Odell presented February 13, 1974.

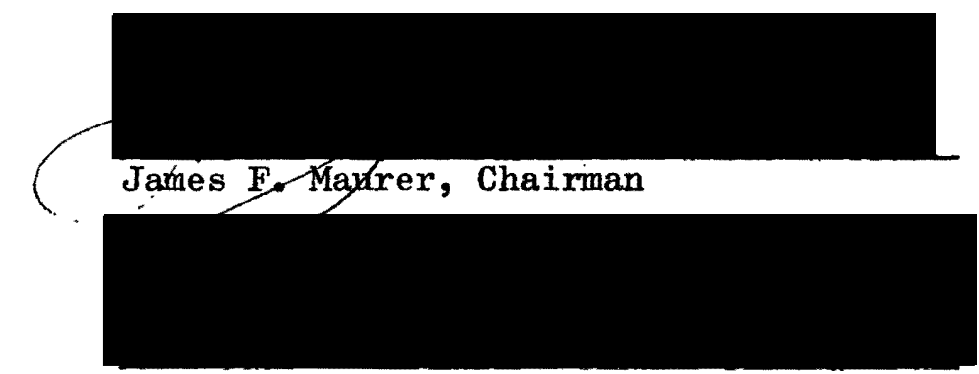

$$
\text { Theodore G. Grove }
$$
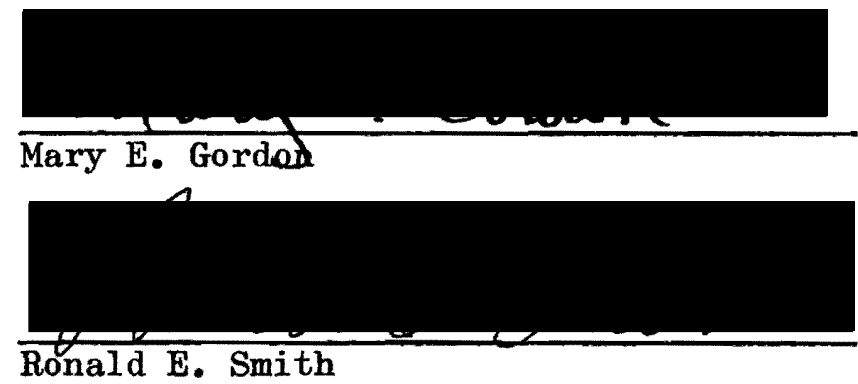

\section{APPROVED:}

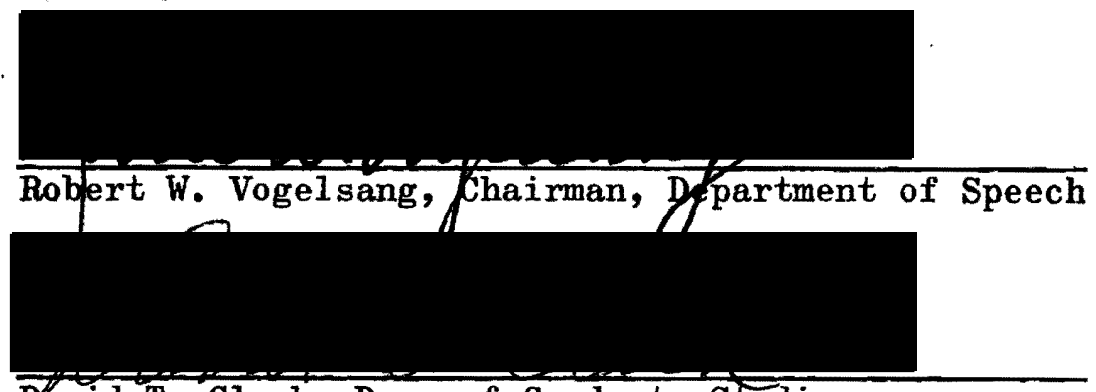

David T. Clark, Dean of Graduate Studies

February 21, 1974 


\section{ACKNOWLEDGMENTS}

This study is the result of the efforts of many wonderful persons who gave of themselves unselfishly.

My special gratitude to Mr. George Frye, President of Frye Electronics, for providing the initial inspiration and the AGC circuitry for this study and for making his laboratory and personal expertise so readily available, while preparing the amplifier for the experiment. Also my special gratitude to Stephen A. Fausti, Ph.D., Chief of Audiology Services at the Veterans Administration Hospital, Portland, Oregon, for permitting me complete accessibility to the well equipped clinical facilities at the hospital, and for his thoughtful suggestions regarding research design.

I am especially grateful to my thesis chaiman, Dr. James F. Maurer, Ph.D., for his many encouragements and suggestions, particularly during preparation of the final manuscript. He gave of his time to me selflessly as a friend. And to the other members of my thesis committee, Dr. Theodore G. Grove, Ph.D., Ms. Mary E. Gordon, and Dr. Ronald E. Smith, Ph.D., my sincere thanks for their kind assistance-and invaluable advice.

Also, I appreciate the technical assistance rendered to me by Mr. Dale Aufrecht and Mr. Garve Beckham of Tektronix, Inc. 
And to my most loving wife, Peggy, and to my parents, I cannot begin to express my gratitude for their unending patience and encouragements.

PRAISE THE LORD! "And we know that all things work together for good to them that love God, to them who are the called according to His purpose." (Romans 8:28) 
TABLE OF CONTENTS

PAGE

ACKNOWLEDGMENTS . . . . . . . . . . . . . . •

LIST OF TABLES • • • • • • • • • • • • • • • •

LIST OF FIGURES . • . • . . . . . . . • . • . •

CHAPTER

I INTRODUCTION •. . . . . . . . . . . . . 1

II HISTORY • . . . . . . . . . . . . 13

Statement of the Problem . . . . . . . 15

III METHODS AND PROCEDURES . . . . . . . . 16

Subjects . . . . . . . . . . . 16

Testing Environment . . . . . . . . 16

Discrimination Test . . . . . . . 17

Equipment . . . . . . . . . 18

IV RESULTS AND DISCUSSION . . . . . . . . . . 24

Results ................ 24

Discussion . . . . . . . . . . 26

V CONCLUSIONS AND IMPLICATIONS • • • • • • • . 32

Summary . . . • . . . . . . . 32

Conclusions . . . . . . . . . . 33

Implications . . . . . . . . . . 34

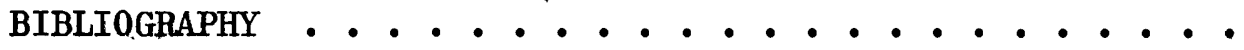


PAGE

APPENDIX A . . . . . . . . . . . . . . . . . .

APPENDIX B . . . . . . . . . . . . . . . . . .

APPENDIX C . . . . . . . . . . . . . . . . .

APPENDIX D . . . . . . . . . . . . . . . . . . 


\section{LIST OF TABLES}

TABLE

PAGE

I Relative Phonetic Power of English Speech Sounds as Produced by an Average Speaker . . . . . .

II Typical Output Characteristics of Three Types of AGC Circuitry ............. . 10

III Sample Sentences from PAL-8 Test . . . . . . . . 17

IV. Stimulus Presentation Order of Forms A, B, C, and D . 22 
LIST OF FIGURES

FIGURE

PAGE

1 A Comparison Between a Sine Wave and a Voiced

Vowe1 . . . . . . . . . . . . .

2 The Sensation Level and Formant Frequencies of

Speech Sounds Plotted Graphically . . . . . 3

3 An Example of a Sine Wave Which is Peak clipped . . 5

4 A Comparison of a Sine Wave Before and After

Peak Clipping ............ . . 6

5 A Block Diagram of an Amplifier with AGC . . . . 8

6 Idealized Gain Characteristics of Various Types

of AGC Circuitry . . . . . . . . . . 9

7 An 0scilloscope Envelope Display of a Typical

Signal Which Has Been Subjected to Limiter

Compressor Action . . . . . . . . .

8 Block Diagram of Procedure Utilized to Develop

Composite Test Presentation Tape ...... 20

9 Speech Noise Spectrum . . . . . . . . . 21

10 Histograms Expressing Mean Error Scores on the

PAL-8 Test According to A). AGC Mode, B) Sex

of Subjects, c) Presentation Order of

Sentence Groups . . . . . . . . . . . 24 
11 A) Pure Tone Sine Wave, B) Typical Speech Signal .

12 A) Pure Tone Sine Wave Undistorted, B) Puxe Tone Sine Wave Peak Clipped . . . . . . . 28

13 A Typical Speech Signal Being Peak Clipped . . . . 29

14 Experimental Fast Attack AGC Envelope Display . . 31

15 Experimental Slow Attack AGC Envelope Display • • 31 


\section{CHAPTER I}

\section{INTRODUCTION}

Speech as it is encoded by the human ear is a learned perception of variations in two basic physical acoustic phenomena: 1) the rate at which sound waves repeat themselves (i.e., frequency, or Hertz) and 2) sound pressure level (which is related to the intensity or power of the sound waves). An example of a pure tone is graphically represented by the oscilloscope trace shown in Figure 1A. For illustrative purposes this may be contrasted with a typical vowel vocalization in Figure 1B. Speech represents a composite of pure tone energies of varying frequency and intensity which results in a complex sound, combining a variety of pure tone harmonics. Complex harmonic sounds are generated as air passes through the vocal folds in the larynx. Controlling the size, shape, and use of pharyngeal, oral, and nasal cavities causes sound produced by the larynx to have major resonances at two or three frequencies unique to each speech sound. At these points of resonance, peaks of energy or intensity are created which are referred to as formants (Fletcher, 1953).

Sanders (1971) pointed out that it is essential for the first two formant frequencies to be perceived for proper identification of vowel sounds. Consonant sounds are usually more dependent upon their high frequency components for proper identification, lacking well defined formant regions. Table $I$ indicates the relative phonetic power of 


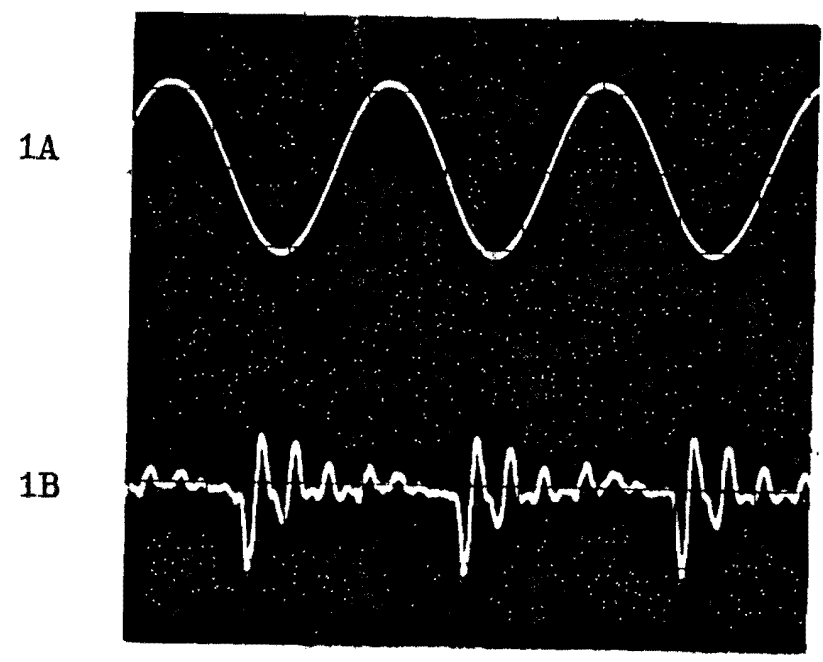

Figure 1. $1 \mathrm{~A}$ is an undistorted sine wave which is representative of an acoustically pure tone. $1 \mathrm{~B}$ is an oscilloscope trace of a voiced vowel sound.

speech sounds as produced by an average speaker. Figure 2 graphically plots the intensities and formants associated with these sounds. It is apparent that much of the acoustic information for consonants lies in the higher frequency region, offering relatively low acoustic intensities when compared to the generally low frequency, higher intensity of the vowel sounds.

The consequences of such frequency-intensity relationships become apparent when one realizes most sensori-neural hearing losses begin in the high frequency region where the voiceless consonant sounds such as $/ \mathrm{f} /, \mathrm{p} / \mathrm{l} / \mathrm{s} /$, etc. (see Figure 2), are located. The result is a loss in the intelligibility of consonant sounds which may easily become masked by environmental noise such as one may encounter on the street, at a party, or in an auditorium (Denes, 1969; Fletcher, 1953; Sanders, 1971). 
TABLE I

RELATIVE PHONETIC POWER OF ENGLISH SPEECH SOUNDS AS PRODUCED BY AN AVERAGE SPEAKER

\begin{tabular}{|c|c|c|c|c|}
\hline 0 & 680 & 1 & 100 & $t$ \\
\hline $\mathbf{a}$ & .600 & $\int$ & 80 & $\mathrm{~g}$ \\
\hline $\boldsymbol{\Lambda}$ & 510 & $\eta$ & 73 & $\mathrm{k}$ \\
\hline$æ$ & 490 & $\mathrm{~m}$ & 52 & $v$ \\
\hline $\mathbf{U}$ & 460 & $\mathrm{t} \int$ & 42 & ð \\
\hline$\varepsilon$ & 350 & $\mathrm{n}$ & 36 & $b$ \\
\hline $\mathrm{u}$ & 310 & $\mathrm{~d}_{3}$ & 23 & d \\
\hline I & 260 & 3 & 20 & $\mathrm{p}$ \\
\hline i & 220 & $\mathrm{z}$ & 16 & f \\
\hline$\Gamma$ & 210 & $\mathrm{~s}$ & 16 & $\theta$ \\
\hline
\end{tabular}

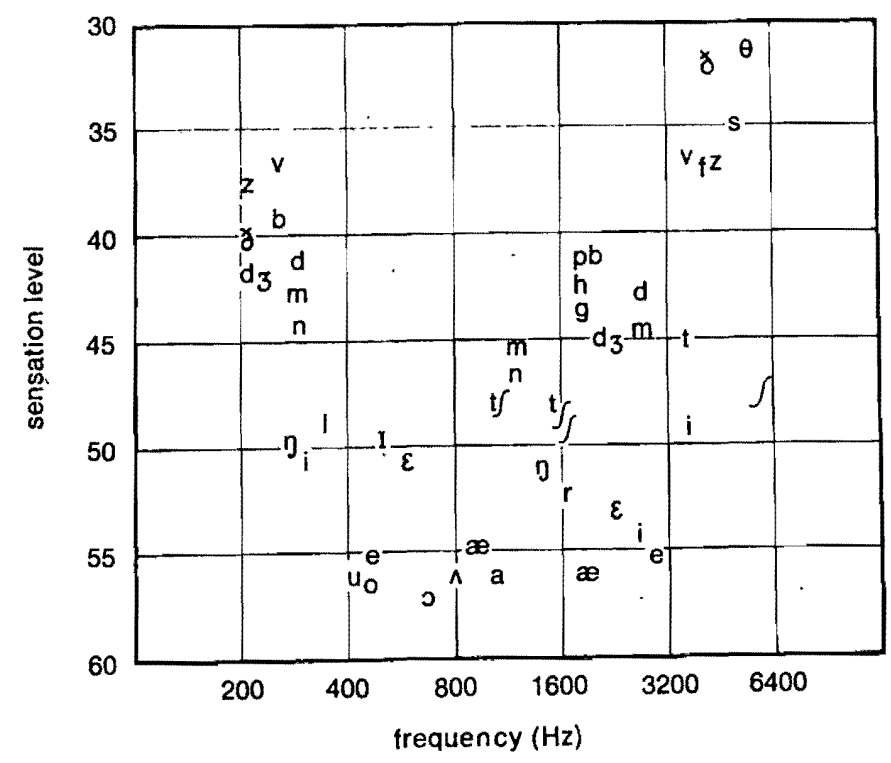

Figure 2. The sensation level and formant frequencies of speech sounds are plotted graphically. The sounds of weakest intensity are near the top of the graph and the low frequencies are to the left (from Sanders, 1971). 
The loss of speech sounds due to an organic hearing deficiency is often overcome through the use of an electro-acoustic amplifying system (i.e., a hearing aid), which is capable of reproducing a dynamic range of sound to include the weakest through the most intense sound pressure levels generated for speech. A conventional linear gain amplifier is commonly utilized for this task. The linear amplifier has constant gain characteristics throughout its designed operating range. For example, a linear amplifier with $50 \mathrm{~dB}$ (decibel) gain will amplify a $20 \mathrm{~dB}$ input signal to $70 \mathrm{~dB}$ output and a $70 \mathrm{~dB}$ input signal to $120 \mathrm{~dB}$ output. Should the input increase $10 \mathrm{~dB}$, the output likewise would increase $10 \mathrm{~dB}$. There is a systematic relationship between the input and output; any given decibel change at the input should result in a similar decibel change at the output until the output limits of the amplifier are reached. When this happens, the output no longer increases at a rate directly proportional to the input, and the amplifier is said to be entering a state of overload referred to as the amplifier's maximum peak output (MPO). In other words, the systematic relationship between input and output is no longer linear. As the amplifier reaches MPO, the peaks of the signal are no longer being reproduced. Rather they are being clipped; hence the term "peak clipping" is used to describe this phenomenon (see Figure 3). Peak clipping is a method frequently used in linear amplifiers to limit the maximum sound pressure level at the amplifier's output.

Whenever an amplifier distorts a sine wave, harmonics are introm duced into the output signal (Lurch, 1971). The extreme peak clipping seen on the right side of Figure 3 may help to visualize the presence 


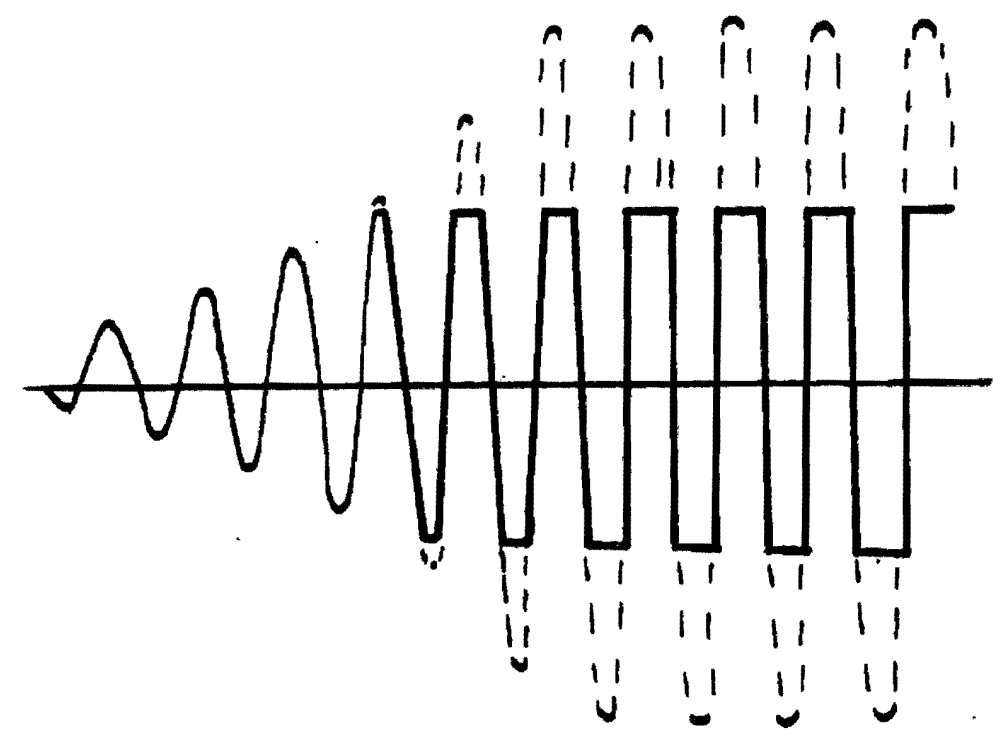

Figure 3. An illustration of peak clipping as the amplitude of a sine wave maximum exceeds amplifier output.

of harmonics. The clipped waveform closely resembles that of a square wave, the composition of which consists of sine waves representing the fundamental frequency and, theoretically, all of its odd harmonics (at intensities following a mathematical odd harmionic progression). The addition of harmonics to form a composite square wave may be demonstrated by a method known as the "addition of ordinants" (Hirsh, 1952; Lurch, 1971; Peterson, 1958; Protter, 1964; Sears, 1961). Figure 4 is an oscilloscope display of a sine wave before and after peak clipping. The oscilloscope vertical gain was adjusted to maintain like amplitudes for purposes of illustration.

Such distortion of speech communication does not present a very serious problem for the vowel sounds since, as can be noted in Figure 2, they are clustered together at the lower to mid-frequencies with high intensity levels. They will not experience much influence from 


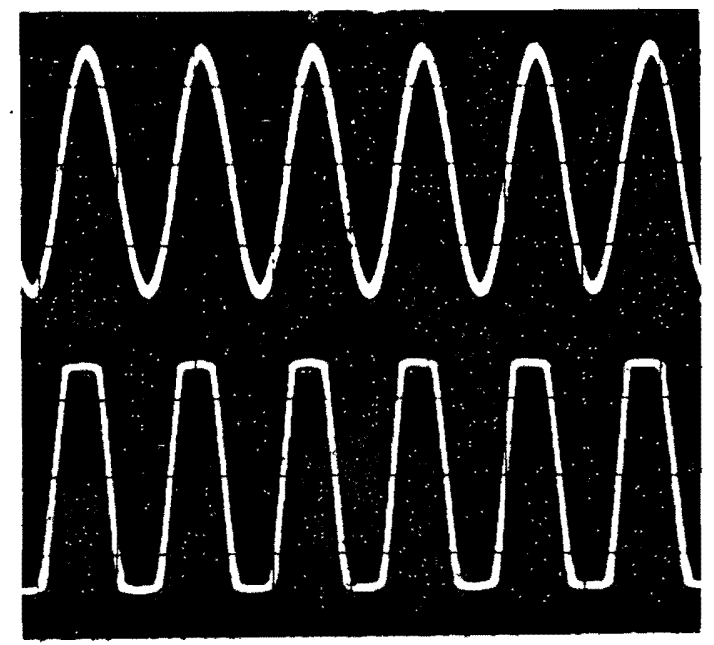

Figure 4. An oscilloscope display of a sine wave before and after peak clipping. The upper trace is the undistorted sine wave; the lower trace is the sine wave after peak clipping.

harmonics which are both higher in frequency and significantly lower in intensity level. However, the higher frequency harmonics of the vowel sounds can interfere with the intelligibility of the more delicate high frequency consonant sounds since the harmonics generated by the vowel sounds may occur within the same frequency and intensity range as the fundamentals of the voiceless consonant sounds. Consequently, the sounds which are already the most difficult to perceive under ideal listening conditions are either partially or completely masked by harmonic distortion.

When such a linear amplifier is used in a hearing aid several other potential problems arise. A second situation is encountered when the output signal of the amplifier is driven beyond the hearing aid user's uncomfortable loudness level (UCL). This'is a particularly important problem if the listener has a hearing pathology which includes a depressed dynamic listening range and a UCL significantly below that 
of the normal listener. The third problem is the amplification of unwanted sounds, which will, in an environment with a poor signal-tonoise ratio; serve as a masking effect for the speech signal. This is a common complaint of persons experiencing sensori-neural hearing pathologies.

In order for an amplifier to reproduce all the phonemes necessary to understand speech in a variety of environments, the amplifier should be capable of amplifying both sounds of very low and relatively high intensities. In other words, the amplifier system should accommodate a wide dynamic range. If the amplifier is to be an effective prosthetic hearing device, it must be capable of amplifying this dynamic range without introducing excessive distortion in the amplified signal. To accomplish this and avoid some of the previously mentioned problems, the linear amplifier has been modified with circuitry often referred to as automatic-volume-control (AVC) or automatic-gain-control (AGC). Although these terms are often used interchangeably, the field of electronic engineering usually makes a distinction according to the design of the amplifier in which the automatic circuitry is incorporated (Lurch, 1971). The term AGC is reserved for the category of amplifier usage which is most likely to include hearing aids.

AGC accomplishes, electro-acoustically, much the same effect as manually rotating the volume control to limit the output of the hearing aid amplifier. The exception to this analogy is that an electronic AGC circuit is much more efficient, faster, and accurate. AGC compression of the output dynamic range helps prevent the amplifier from exceeding 
its MP0 while at the same time increasing the input dynamic range of the amplifier.

Figure 5 is a block diagram of a representative hearing aid amplifier with AGC circuitry. An input signal $\left(S_{i}\right)$ is fed to the input amplifier, it is amplified, and the amplified signal from the output amplifier $\left(S_{0}\right)$ is measured by the detector (AGC circuit) and rectified to a direct current (DC) level which is proportional the output, $\mathrm{S}_{0}$. This DC level $\left(S_{f}\right)$ is fed back to the input amplifier to provide a negative bias, which in turn reduces the gain of the amplifier. In other words, when the output signal becomes sufficiently intense, the AGC circuit introduces a negative feedback, $S_{f}$, which reduces the output. Likewise, the detector will also sense a significant reduction in the output signal and within a specified time, as determined by circuit design, the $S_{f}$ level is turned off, returning the amplifier to a condition of linear gain (Burger, 1970; Carver, 1972; Lurch, 1971; Stuart, 1940).

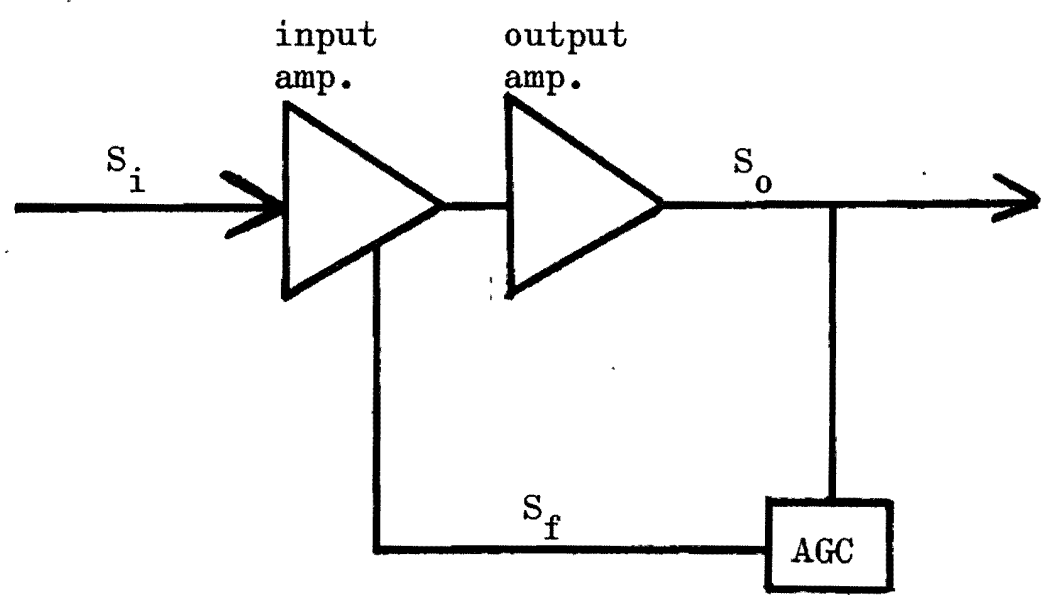

Figure 5. A block diagram of an amplifier with AGC. The input signal $\left(S_{i}\right)$ is amplified by the amplifier and the output signal $\left(\mathrm{S}_{0}\right)$ powers the tranducer for the ear. The feedback signal $\left(S_{f}\right)$ reduces the amplifier gain. 
Hearing aid amplifiers which utilize AGC circuitry are said to be compression amplifiers. There are three types of compression amplifiers utilized in currently produced hearing aids: A) linear compressors; B) non-linear compressors; C) limiter compressors. The AGC circuit operation described previously is a limiter compressor (Berger, 1970). Figure 6 is a graphical comparison of the output characteristics of the three types of AGC circuitry. Table II is a tabular comparison of the same AGC circuits. Briefly, these circuits differ in their operation

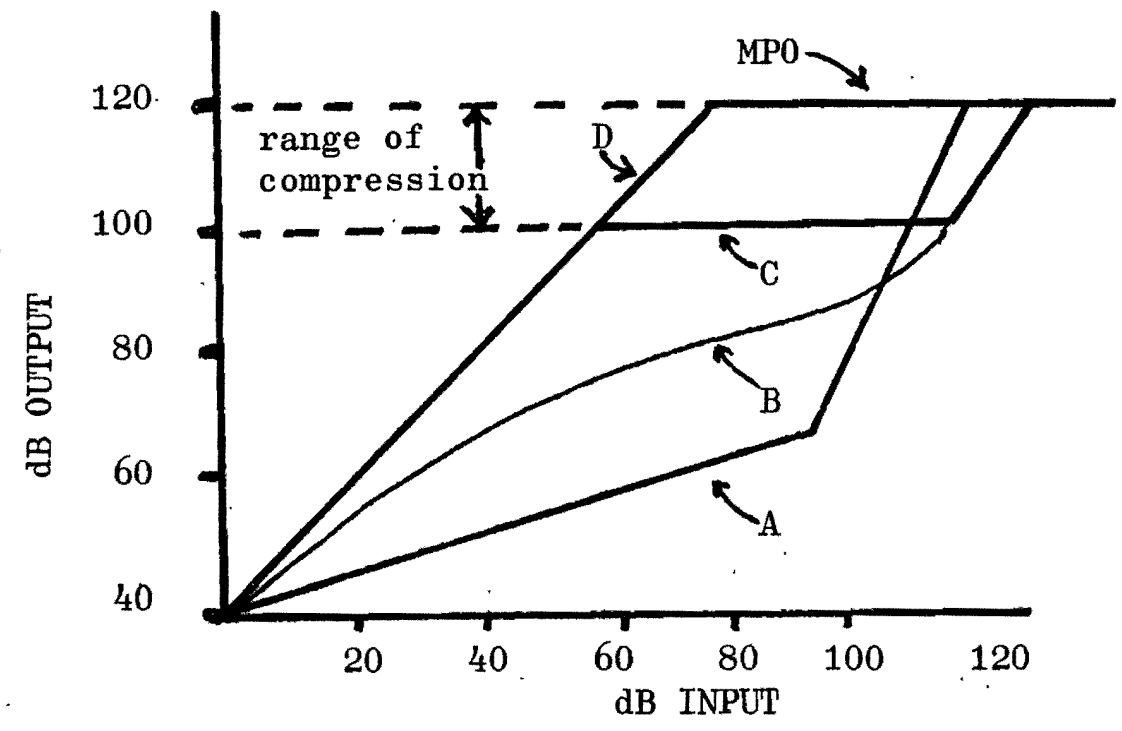

Figure 6. A graphical representation of ideal gain characteristics of the types of AGC circuitry discussed. A) linear compressor; B) non-linear compressor; C) limiter compressor; D) linear amplifier without compression circuitry.

as follows: Curve A) The linear compressor begins its compression action at its very lowest input levels and amplifies at a continuous ratio throughout its operating range. If, for example, it is designed for a 2:1 ratio, an input signal increase of $20 \mathrm{~dB}$ will increase the output $10 \mathrm{~dB}$. When the AGC circuitry can no longer reduce the amplifier gain, further increases of the input signal will put the amplifier in a state 
TABIE II

TYPICAL OUTPUT CHARACTERISTICS OF THREE TYPES AGC CIRCUITRY INCORPORATED IN A

FORTY dB GAIN AMPLIFIER

\begin{tabular}{|c|c|c|c|c|}
\hline \multirow[b]{2}{*}{$\begin{array}{l}\text { dB INPUT } \\
\text { INCREASE }\end{array}$} & \multicolumn{4}{|c|}{ dB OUTPUT INCREASE } \\
\hline & $\begin{array}{c}\text { No } \\
\text { Com- } \\
\text { pression }\end{array}$ & $\begin{array}{c}\text { Linear } \\
\text { Com- } \\
\text { pression }\end{array}$ & $\begin{array}{c}\text { Non-linear } \\
\text { Com- } \\
\text { pression }\end{array}$ & $\begin{array}{c}\text { Limiter } \\
\text { Com- } \\
\text { pression }\end{array}$ \\
\hline 0 & 40 & 40 & 40 & 40 \\
\hline 20 & 60 & 50 & 55 & 60 \\
\hline 40 & 80 & 60 & 70 & 80 \\
\hline 60 & 100 & 70 & 85 & 100 \\
\hline 80 & MPO & 80 & 95 & 100 \\
\hline 100 & MPO & 90 & 100 & 100 \\
\hline .105 & MPO & MPO & 100 & 100 \\
\hline 110 & MPO & MP0 & MP0 & 100 \\
\hline 115 & MP0 & MPO & MPO & MPO \\
\hline
\end{tabular}

of MP0. Curve B) The non-linear compressor may have very little compressor action at very low input levels, but as the input signal becomes more intense a continuously greater per cent of the output is compressed until the limits of compression are reached. The amplifier will then proceed to a condition of MP0, but at a higher input than an amplifier without compression or a linear compressor. Curve C) The limiter compressor operates as a linear amplifier without compression circuitry, i.e., at a $1: 1$ ratio until the AGC circuitry begins reducing the gain. The point at which this occurs is called the threshold of compression (TC) and is commonly designed at a level between 115 and $120 \mathrm{~dB}$ (Berger, 1970). As with the previously mentioned types of AGC circuits, the amplifier output using a limiter compressor (Curve C) will also enter a state of MPO as additional input is added after it has reached its limits of compression. 
There are two major benefits associated with the limiter compressor as opposed to the other forms of compression mentioned. One involves the ability to provide maximum amplification of the very low intensity sounds and yet limit amplification for high intensity sounds. The other advantage is a greater dynamic range of operation before the limits of compression are exceeded (see Figure 5).

A disadvantage to limiter compression (Curve C) is its inability to react instantaneously. There is typically a 4 millisecond (ms) to $50 \mathrm{~ms}$ time delay in attenuation after the sound has attained the threshold of compression. This onset delay is called the "attack" time. Likewise, there is a time delay from the point at which a compressed signal is reduced below the TC until the AGC releases the control of the gain. This phenomenon is referred to as the "release" time.

Figure 7 is an oscilloscope envelope display of a typical audio signal which has been subjected to limiter compressor action. Beginning at time zero is a normal uncompressed steady-state signal. The time interim between 1 and 2 is the "attack" time. The distance the signal extends above the steady-state AGC level is the "overshoot." The interim between 2 and 3 represents the time necessary for the AGC to reach its steady-state level after the "attack" and is called the recovery time. Point 3 represents the beginning of steady-state AGC operation. At point 4 the signal is reduced to below the TC. It may be noted at this point in Figure 7 that the AGC has not yet released its control of the signal, so that the smaller signal is also compressed for a small period of time. The release time is represented by the time interim between points 4 and 5 . 


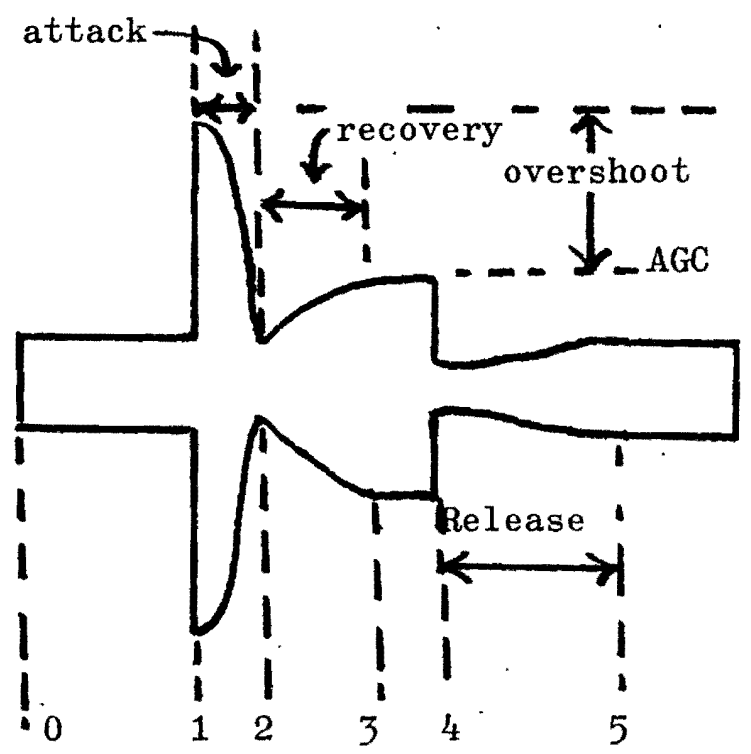

Figure 7. An oscilloscope envelope display of a typical audio signal which has been subjected to limiter compressor action. 1 to 2 is the attack time, 2 to 3 is the recovery time, and 4 to 5 is the release time.

Those phases represented in this graphical illustration which are considered to be of most importance to hearing aid designers are the attack and release times. The attack time of the AGC unit must be longer than the time necessary to complete one full cycle of the lowest frequency that the amplifier is designed to pass. Most commercial hearing aids available today have attack times of $50 \mathrm{~ms}$ or less. If the attack time is not long enough, the AGC circuit would interpret the rise time of each low frequency sine wave as the onset of separate signals rather than measuring the content of the signal as a whole. This can result in a distorted signal, which would sound like a flutter if the recovery time were also relatively short. Because of the relatively slow rate at which syllables are uttered (100 to $150 \mathrm{~ms}$ average), release times commonly range from $50-150 \mathrm{~ms}$ in hearing aid circuits (Berger, 1970; Carver, 1972; Rintelman, 1972). 


\section{CHAPTER II}

\section{HISTORY}

In the early history of radio broadcasting, volume control for the transmitted signal was accomplished manually. When the program material became too loud, a technician had to lower the volume and as the sound level returned to normal the volume had to be increased again. Particularly disturbing were sudden loud noises. The technician operating the volume control had extreme difficulty acting rapidly enough to reduce the sound level before the members of the listening audience were elevated from their seats. What was needed was a robot with inhumanly fast reaction time, continuously alert to the changing program material, and never tiring of his job.

By the late thirties and early forties a method of negative feedback was implemented to limit the output of such amplifying circuits (Black, 1941; Cook, 1939; Stuart, 1940). The first electro-acoustic hearing aids were produced around the turn of the century, and by the time methods of automatically limiting gain were developed, it seemed apparent this type of circuitry might have some utility for hearing aid users also (Davis, 1947; Hudgins, 1948). The difficulty was that the state-of-the-art in electronics was insufficiently developed to produce a limiter circuit small enough to fit into a wearable hearing aid.

A study reported in 1948 , by Hudgins, et al., comparing a master hearing aid and an experimental hearing aid, both equippped with AGC 
circuitry, to two commercially available hearing aids without compression circuitry, indicated the hearing impaired person would derive benefit from utilizing AGC. One of the first reported uses of automatic gain control in a commercially available hearing aid was produced by a European manufacturer. This was designed to be used as a nonportable desk type amplifier and was larger than many of today's dictating recorders (Berger, 1970; Poliakiff, 1950; Caraway, 1966).

Commercially produced, wearable hearing aids with automatic gain control began to appear on the market in the United States in 1949 . It was not long before more critical testing and experimentation began, in order to evaluate how more effectively compression circuitry improved speech intelligibility than conventional linear amplifiers using peak clipping to limit maximum output (Edgardh, 1952; Parker, 1953). The results were impressive and supportive in favor of the compression type circuitry.

Later, in 1960, Kretsinger and Young reported a study comparing two degrees of fast limiting compression ( $10 \mathrm{~dB}$ and $20 \mathrm{~dB}$ ) to peak clipping of the same degrees to evaluate their relative effect on intelligibility of speech. As in the earlier studies, it was apparent that using peak clipping to restrict the maximum output would limit the listener's ability to achieve good intelligibility scores more than either of the compression limiters.

In 1963, Lynn and Carhart reported on a study in which a variety of attack and release times were compared. Due to the large number of compression limiters being built and used in hearing aids, such study was not unreasonable. The study utilized nine circuits which compared 
attack times ranging from $5 \mathrm{~ms}$ to $85 \mathrm{~ms}$ and release times from $30 \mathrm{~ms}$ to $1200 \mathrm{~ms}$. A conventional fixed gain amplifier was also utilized as a basis for comparison. Two measures of effectiveness were used. The first incorporated speech reception threshold measurements as recorded by hearing threshold dial readings, and the second measured intelligibility using Phonetically Balanced (PB) words. The subjects were divided into three groups: those with pathologies of otosclerosis, labyrinthine hydrops, and presbycusis. It was concluded the otosclerotics received minimal benefit from compression regardless of the time constants. The remaining subjects appeared to derive significant benefit from the use of the limiter compression amplification with maximum results occurring when attack and release time constants were about $5 \mathrm{~ms}$ and $150 \mathrm{~ms}$, respectively. The authors of the study emphasized that primary consideration must be given to the user's needs, the type of compression system used, and the levels and varieties of sounds he might encounter in his environment.

Statement of the Problem

Studies to date have been concentrated in the area of evaluating attack times for fast limiters. There is no available information indicating how speech intelligibility, when assessed with a sentence discrimination task, is affected by a limiter compressor which utilizes long attack and release times. There is the possibility of improved performance through the utilization of attack times which are more than $500 \mathrm{~ms}$. The purpose of this study is to compare the intelligibility of speech through an amplifier with a fast attack time and a slow attack time utilizing a sentence discrimination task. 
CHAPTER III

\section{METHODS AND PROCEDURES}

It is the intent of this study to compare two rates of limiter compression and study (analyze, etc.) their relative effects on speech intelligibility using a sentence discrimination task. The hypothesis may be stated as follows: There is a difference in intelligibility of speech when compared through fast and slow attack AGC circuits. The methods and procedures used to conduct this study are outlined below.

\section{SUBJECTS}

Twenty-four normal hearing young adults were selected to serve as subjects for this experiment. There was no attempt to balance the subjects according to sex. In order to control for possible effects of age or auditory pathologies, subjects were chosen according to the following criteria: 1) normal hearing as determined by pure tone thresholds of $10 \mathrm{~dB}$ (ANSI 1969) or better at frequencies of 250,500, 1000, 2000,4000 , and 8000 Hertz; 2) ages from eighteen to thirty years; 3) no previous history of excessive noise exposure; 4) a negative history of hearing pathologies.

\section{TESTING ENVIRONMENT}

All testing was conducted in single-walled Industrial Acoustics Company (IAC) sound treated rooms located in the Veterans Administration 
Hospital Audiology Service, and the Portland State University Speech and Hearing Sciences Audiological Testing Environment, Portland, Oregon (models 404 and SP 403, respectively).

\section{DISCRIMINATION TEST}

The Harvard University Psychoacoustic Laboratory (PAL) sentence discrimination test number 8 (PAL-8) was utilized. Two studies (Jerger, $1966_{a}$; Jerger, 1966 $6_{\mathrm{b}}$ ) indicated the PAL-8 test material had superior capabilities for ranking and ordering hearing aids when compared with the use of phonetically balanced (PB) monosyllabic word discrimination tests. Also, since most hearing aid usage involves listening to continuous discourse, it was deemed more relevant to use a sentence discrimination task rather than PB words. Table III shows two examples of typical sentences used for the discrimination task. These sentences have been constructed in such a manner that the listener must hear most or all of the key words before he can derive the appropriate answer.

TABLE III

SAMPLE SENTENCES FROM PAL-8 TEST

1. What insect does honey come from? hive

bee cricket treasury

2. Underline the smallest sum of money: dwarf flower 5 cents mouse

The test consisted of sixty short sentences which were in the form of questions, commands, or incomplete statements. Each subject 
was instructed to underline the most correct multiple choice response following presentation of the sentence. A complete copy of the test material utilized for the experiment is located in Appendix A.

$$
\text { IV. EQUIPMENT }
$$

\section{Threshold Measurements}

All pure tone threshold measurements were obtained with a Grason and Stadler Model 1701 dual channel automatic audiometer with TDH 49 earphones mounted in MX 41/AR cushions (V.A. Hospital) and a Beltone 15C audiometer with $\mathrm{TDH} 39$ earphones, also mounted in MX 41/AR cushions (PSU). Each audiometer was monitored for correct calibration with a Bruel and Kjaer sound level meter Model 2203 fitted with a thirteen octave band acoustic filter and artificial ear with a 2 cc coupler before and after testing.

\section{$\underline{\text { AGC Limiter }}$}

Two experimental automatic gain control circuits were incorporated in a hearing aid amplifier. The amplifier input and output were modified in such a manner as to match the higher intensity and impedance of the tape recorder output and input, respectively. This engineering represents a necessary alteration in the typical hearing aid amplifier, which has its input and output impedances to match a microphone and receiver, respectively. A schematic wiring diagram of the apparatus is included in Appendix B.

The fast limiter was designed to produce an attack time of $40 \mathrm{~ms}$ and the slow limiter an attack time of $600 \mathrm{~ms}$. In order to limit any 
release time variables in the study, both limiters were designed to produce the same time constants of $650 \mathrm{~ms}$. A Tektronix 5310 dual beam oscilloscope was utilized to measure the actual time constants of the AGC amplifier. The activating signal was a 1000 Hertz sine wave.

\section{Stimulus Tape Recording}

The master recording of the PAL 8 test stimuli was made in the IAC Model 404 audiometric test booth described in the testing environment section. Sixty PAL-8 sentences were read into an AKG Model D200E dynamic studio recording microphone connected to a Teac 7030SL tape recorder. Maxell UD 50 extended range high fidelity recording tape was the medium for recording. The sentences were read at ten-second intervals. This procedure resulted in an unmodified recording of the sentences (see Figure 8). The recorded list of sixty sentences was then: 1) routed through the hearing aid circuit modified by the slow attack AGC and dubbed onto track 1 of another tape and 2) routed through the hearing aid circuit modified by the fast attack AGC and recorded on track 2 of the other tape. The dubbing tape recorder which recorded the AGC modified signals was a Tandberg $4000 \mathrm{X}$ tape deck.

During the dubbing process the AGC amplifier gain was adjusted to provide the amplified running discourse intensity peaking at approximately $8 \mathrm{~dB}$ above the threshold of compression. The AGC amplifier input and output were continuously monitored by a Tektronix Model 5310 dual beam oscilloscope to ascertain that proper gain and compression relationships were maintained. 
1)

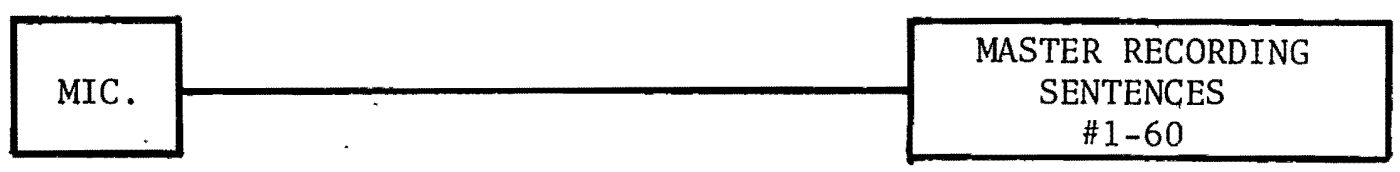

2)

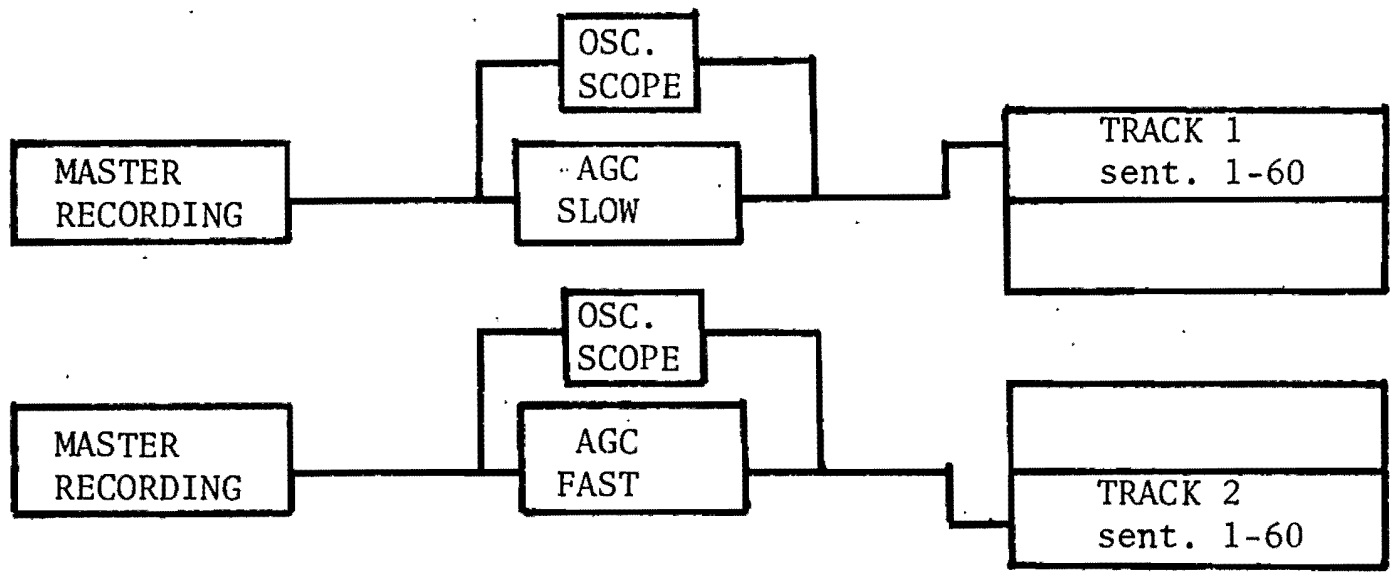

3)

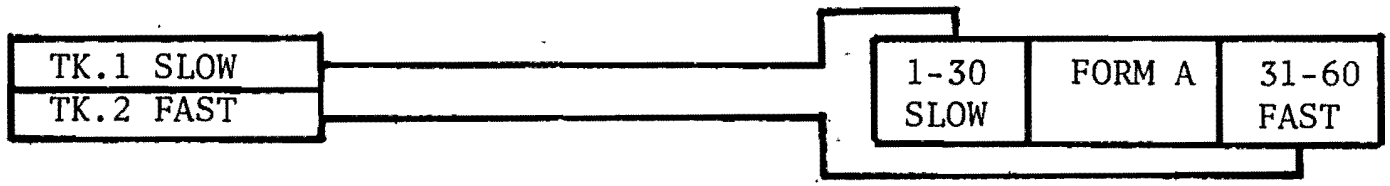

5)

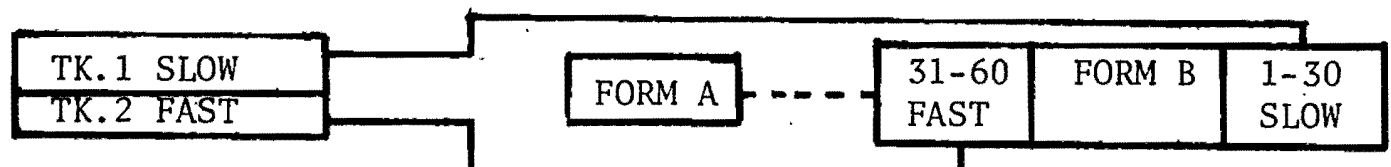

6)

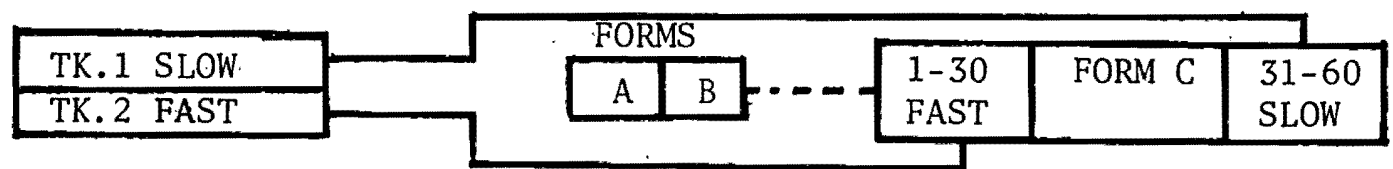

7)

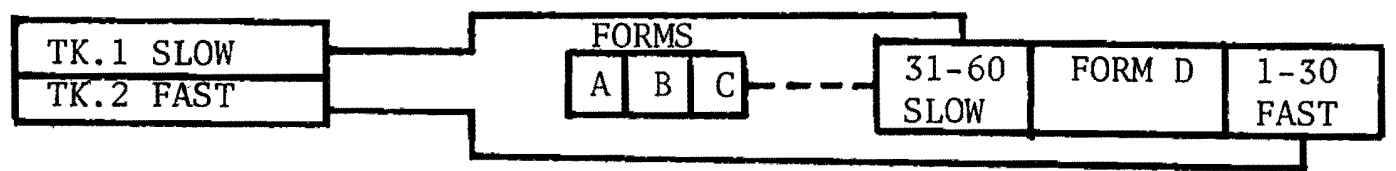

8)

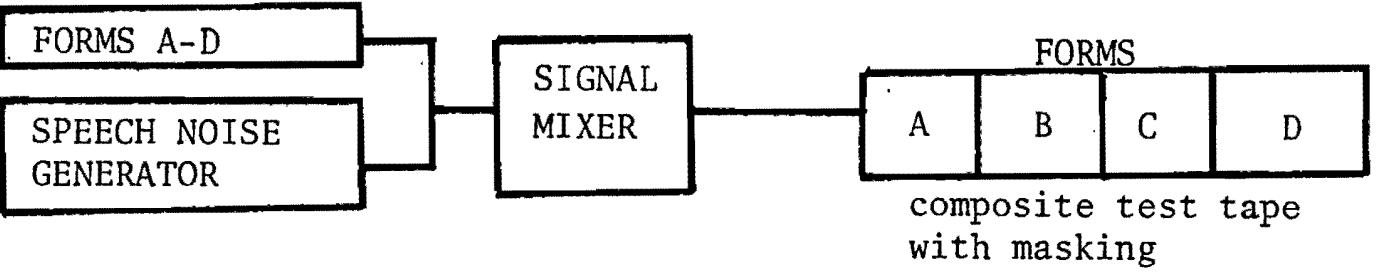

Figure 8. Block diagram showing the procedure utilized to develop composite test presentation tape. 
The final recording used for the stimulus test tape was dubbed from the above described tape and divided into four forms: A, B, C, and D. Forms $A$ and $B$ had sentences 1 through 30 modified by slow attack and sentences 31 through 60 modified by fast attack. Form A presented the slow attack sentences (1-30) first and Form B presented the fast attack sentences (31-60) first. Forms $C$ and $D$ reversed the order of modification. Sentences 1 through 30 were modified by the fast attack AGC. Forms $C$ and $D$ also were arranged so the fast and slow attack sentences were each presented first, as they were for Forms $A$ and $B$.

During the production of the final recording just described above, a signal mixer built into the dubbing recorder (Tandberg 4000X) was utilized to introduce a masking noise which would provide a difficult listening task for normal hearing persons. "Speech Noise," which is a random noise generated and filtered by the Grason Stadler 1701 audiometer, was the masking utilized for this study. The acoustic characteristics of the speech noise are graphically displayed by Figure 9 (Grason Stadler 1701 operating manual).

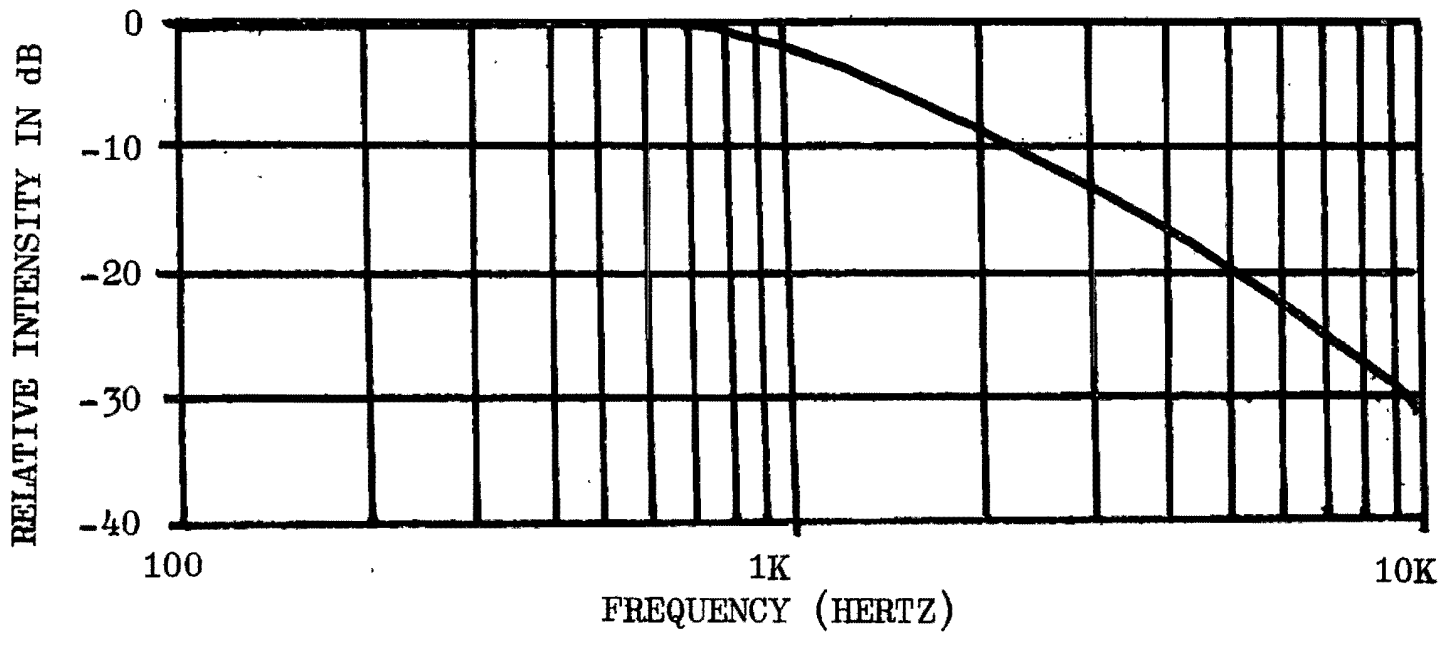

Figure 9. Speech noise spectrum used in Grason Stadler 1701 audiometer. 
A pilot study involving ten normal hearing persons suggested that a $-4 \mathrm{~dB}$ signal-to-noise ratio (the level of the signal was $4 \mathrm{~dB}$ below the intensity of the noise) would result in scores of approximately $65 \%$ when mixed with a signal not modified by AGC circuitry. The $-4 \mathrm{~dB}$ signal-to-noise ratio hence was adopted for the study being conducted.

The net result of producing the test stimulus recording was four forms of stimulus presentation ( $, B, C$, and $D)$, all originating from the same master recording. Irregularities which may have existed in the master recording were represented equally in each mode of signal modification thus balancing effects across treatments. Likewise any order effects, which may have developed during stimulus presentation, and which could have enabled a subject to answer the second thirty sentences with greater accuracy than the first thirty sentences, also were balanced across treatments. Table IV displays the stimulus presentation order of Forms A, B, C, and D. Six subjects were assigned to each of the forms (A-D). Form A was presented to subject $1\left(S_{1}\right)$, Form $B$ to $S_{2}$, -, and Form $\mathrm{D}$ to $\mathrm{S}_{24^{\circ}}$

TABLE IV

STIMULUS PRESENTATION ORDER OF FORMS A, B, C, AND D

\begin{tabular}{|c|c|c|}
\hline & $\begin{array}{c}\text { Presented } \\
\text { First } \\
\end{array}$ & $\begin{array}{l}\text { Presented } \\
\text { Second } \\
\end{array}$ \\
\hline Form A & $\begin{array}{l}1-30 \\
(\text { fast })\end{array}$ & $\begin{array}{l}31-60 \\
(\text { slow })\end{array}$ \\
\hline Form $\mathrm{B}$ & $\begin{array}{l}31-60 \\
(\text { slow })\end{array}$ & $\begin{array}{l}1-30 \\
\text { (fast) }\end{array}$ \\
\hline Form C & $\begin{array}{l}1-30 \\
(\text { slow })\end{array}$ & $\begin{array}{l}31-60 \\
\text { (fast) }\end{array}$ \\
\hline Form D & $\begin{array}{l}31-60 \\
\text { (fast) }\end{array}$ & $\begin{array}{l}1-30 \\
(\text { slow })\end{array}$ \\
\hline
\end{tabular}


CHAPTER IV

\section{RESULTS}

The hypothesis that there is a difference in intelligibility of speech when compared through fast and slow attack automatic gain control (AGC) hearing aid circuits was supported by the data. Figure 10 represents a composite of histograms which display various aspects of these data. Histogram A expresses the mean number of group errors and standard deviations for the fast and slow attack modes. The mean intelligibility error score for the slow AGC group was 6.67 out of a possible total of 30 correct responses, and for the fast AGC group the calculated mean was 8.25 . The differences between mean intelligibility error scores for fast and slow attack AGC circuits were statistically significant at the .05 level of confidence. Histogram B represents an analysis of error scores of male and female subjects within the experimental groups. Females scored lower on the PAI-8 intelligibility test, irrespective of AGC mode, than males, although the differences.between means, 7.93 errors for females and 6.98 for males, were not statistically significant. Histogram $C$ reflects the means and standard deviations of the reversal design in order of sentence group (1-30 and 31-60) presentation. The mean number of intelligibility errors between the sentence group presented first, 7.67 , and the sentence group presented second, 7.25 , did not reveal any differences that could contribute toward an order effect. 


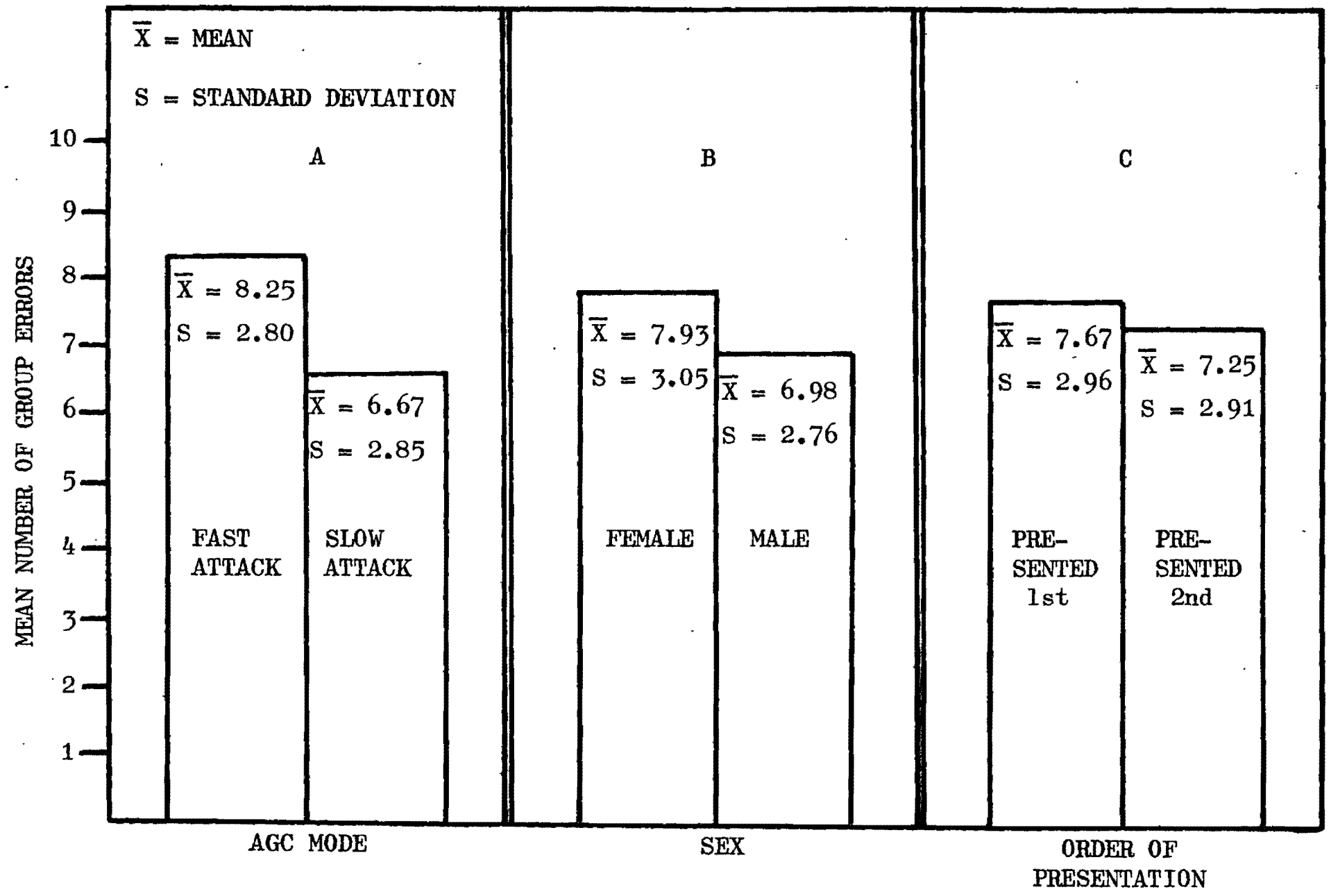

Figure 10. Histograms expressing mean error score on the PAL-8 intelligibility test, according to A) AGC mode, B) sex of subjects, C) presentation order of sentence groups (1-30 and 31-60). 
Since the study necessarily was conducted in two separate testing environments, Portland State University and Veterans Administration Hespital, it was of interest to examine the error scores of the two samples to determine whether the experimental settings were autonomous. The means for the university and V.A. Hospital samples were quite similar, 7.39 and 7.55 , respectively, with standard deviations of 2.90 and 3.0, indicating that separate test environments did not contribute significantly to the outcome of the study.

Finally, the age range of the total experimental sample assigned to the various conditions was 19 to 30 years. No attempt was made to match experimental subgroups on the basis of age; consequently, it was of additional interest to determine whether age was a determining factor in the intelligibility error score on the PAL-8 examination. A Pearson Product Moment correlation (Bruning, 1968) was computed between age in years and number of errors on the test. An extremely low correlation between these two variables $(r=.11)$ suggests that age and error score were not related within this restricted sample. 


\section{DISCUSSION}

1) An evaluation of the data generated by this study indicates the emergence of a concept which may be the converse of that practiced by the hearing aid industry as a whole.

2) The general trend in AGC circuit design is in the direction of reducing the attack times (Berger, 1970; Carver, 1972; Rintelman, 1972). 3) Appárently, some companies are attempting to develop AGC circuits for hearing aids with attack times less than $5 \mathrm{~ms}$ (Hewitt, 1972). This trend toward faster attack times is based on the supposition that the sooner the AGC can become effective after the onset of an excessively intense speech signal, the sooner the peak clipping and harmonic distortion will be eliminated. Accordingly, one would anticipate a resulting speech signal which could be more easily understood. The results of this study indicate the inverse may be true, at least within the limits of the amplifier defined in Appendices B and C. This disparity may be better understood through examination of the experimental AGC amplifier operation.

A study of the acoustic dynamics of the experimental AGC amplifier in operation, revealed the attack circuits reduced the gain much slower for speech signals than for a reference pure tone signal of $1000 \mathrm{~Hz}$. The actual lapsed time the AGC circuits required to achieve full AGC control when subject to experimental test stimuli was measured. The fast circuit had an average lapsed time, from signal onset to full AGC control, of $110 \mathrm{~ms}$. For slow attack the mean lapsed time was 1800 ms. Comparing these figures with those obtained using the reference pure tone signal, the fast AGC circuit was rated at $40 \mathrm{~ms}$ and the slow 
circuit at $600 \mathrm{~ms}$. The significance of this greater lapsed time is that slow AGC may provide better amplified listening conditions than fast AGC for the signal levels utilized in this study. This can be visualized by examining the effect of these modes on signal intensity. The difference in signal amplitude ( 3 to $5 \mathrm{~dB}$ ) between a condition of fast $\mathrm{AGC}$ and slow attack prior to AGC control may be sufficient to produce a significant difference in speech discrimination scores. In marginal listening situations, which were defined in this study by a high level of masking noise introduced after AGC, the non-peak areas of the signal may be more clearly heard through the slow attack circuit than through the fast attack circuit for the period of time the difference exists. This difference between the fast and slow attack outputs may be more clearly visualized if the signal characteristics are analyzed more closely.

Figure 11 shows a direct comparison of an idealized pure tone signal (11A) and a typical speech signal (11B). Figure 12 shows the pure tone signal before and after peak clipping (12A and $12 \mathrm{~B}$ respectively). The portion of the sine wave which has undergone peak clipping represents a large proportion of the horizontal width (time) of the signal. Figure 13 provides an example of the typical speech signal before and after peak clipping, but prior to AGC control of the signal. The center oscilloscope trace is the undistorted signal without peak clipping; the upper and lower traces represent the signal undergoing peak clipping. It may be observed that only the very largest peaks are being clipped. These are very short in time duration, i.e., their horizontal width is very narrow when compared to the width of one cycle of 


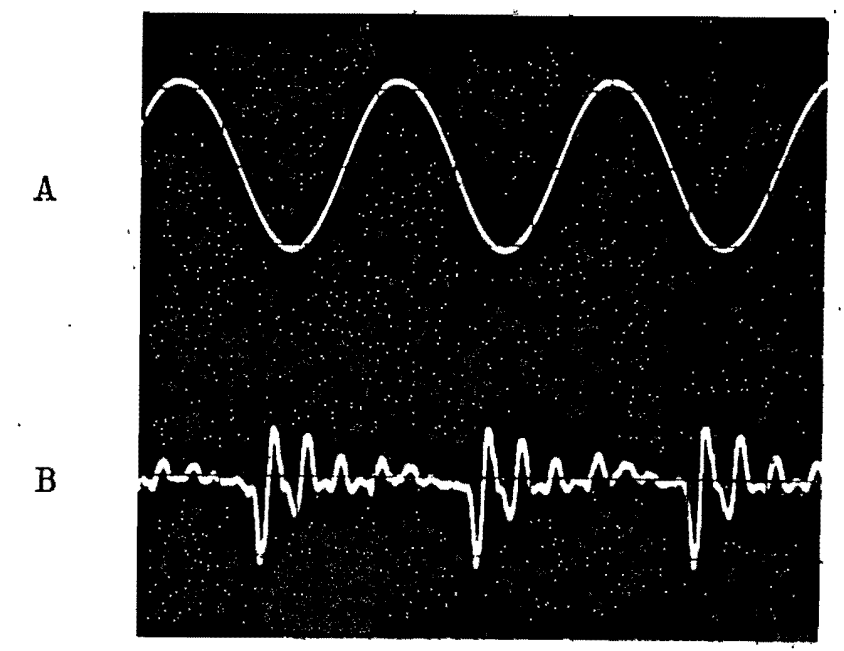

$\frac{\text { Figure } 11 .}{\text { signal. }}$

A) Pure tone sine wave. B) Typical speech

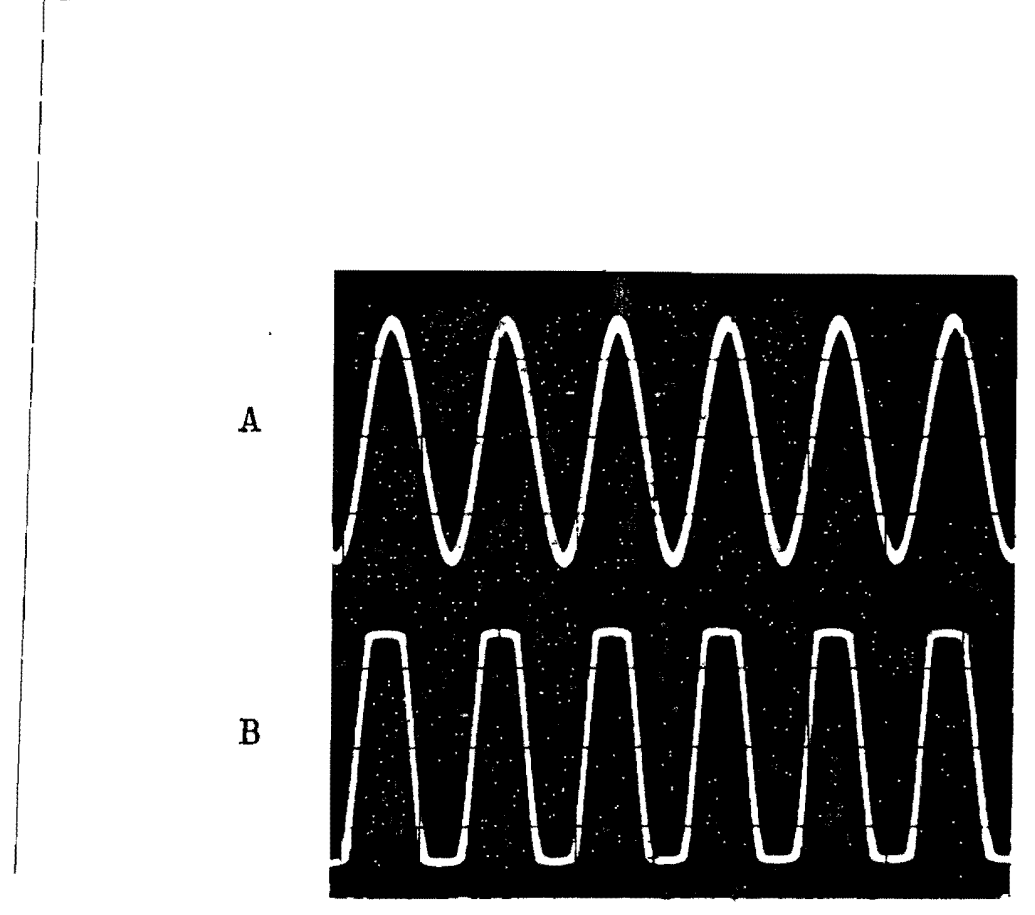

Figure 12. A) Pure tone sine wave undistorted. B) Pure tone sine wave with peak clipping. 


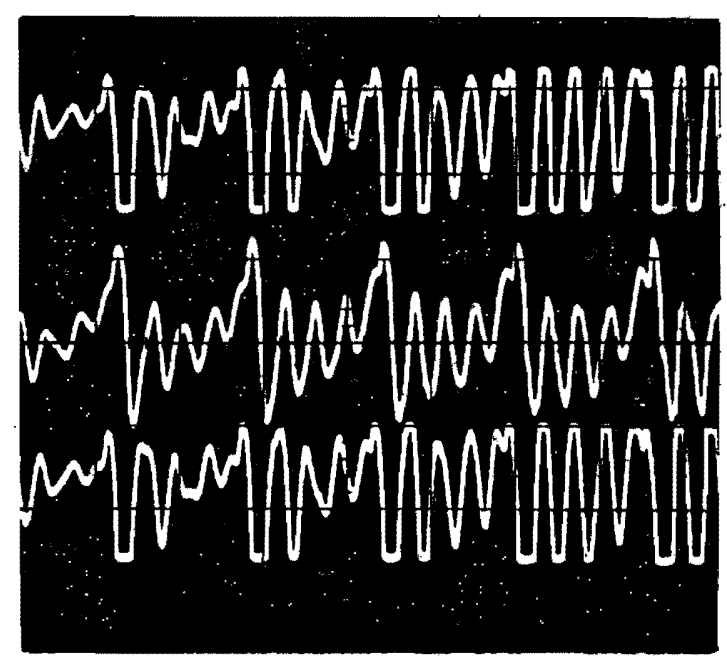

Figure 13. An example of a typical speech signal being peak clipped. The center trace is the undistorted signal. The upper and lower traces are the same signal after peak clipping.

the fundamental frequency.

The above information indicates that unless the amplifier is overdriven so that the signal is more severely peak clipped than it was for this study, the harmonic distortion introduced through the clipping of the narrow peaks may not significantly deteriorate the overall signal quality. Inspection of Figure 13 seems to support this. It can be noted that there has been very little harmonic distortion added to the original signal. This is not to imply the particular condition presently being discussed may be generalized to all other listening environments. The listening conditions presented for this study, for experimental purposes, include only a three-second speech stimulus without any non-related acoustic interaction prior to AGC modification of the signal. 
In order to eliminate independent variables from having an unknown effect on the test results, this investigation was conducted in an acoustically sterile environment, quite unlike a hearing aid user might encounter in everyday life. Most speech signals, when compared to the one used in this study, have much variability in rate and intensity. The speech stimulus utilized for the experiment was presented at a steady rate and peaked at a consistent level (zero dB on a V.U. meter). Sterility of the acoustic environment was further assured by insuring a low background noise level during the recording. A compression type amplifier in a hearing aid is most useful and effective to the user when in an environment with a moderate ambient noise level. A more pragmatic test situation would include introduction of the masking noise with the speech stimulus prior to the AGC circuit.

Finally, the difference in intelligibility scores for the two modes of AGC also may be attributed to the comparatively abrupt change of signal modification of the fast AGC. The transients of the fast AGC might be sufficiently detectable to the subject to impede his maximal ability to discriminate speech sounds. Figures 14 and 15 are actual oscilloscope envelope displays for the AGC circuits utilized for this study. The circuits are being subjected to a sudden $20 \mathrm{~dB}$ sine wave signal which is greater than the TC. Figure 14 displays the abruptness of the signal as it responds to fast attack AGC control. Figure 15 reveals the more gradual envelope of slow AGC response. A speech signal subjected to this form of signal modification is less likely to cause discernible distortion due to AGC transients. 


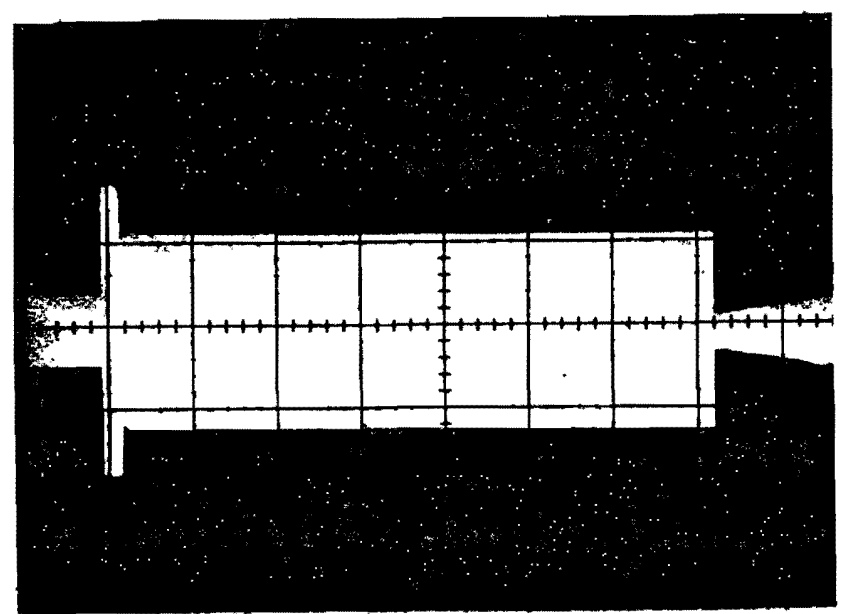

Figure 14. An oscilloscope envelope display of the fast attack AGC operating characteristics when activated with a $20 \mathrm{~dB}$ sine wave pulse.

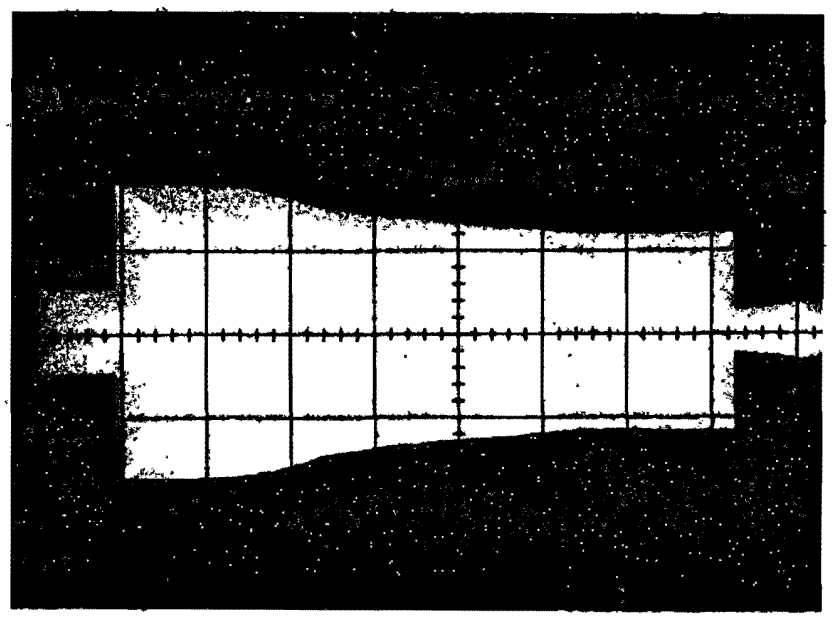

Figure 15. An oscilloscope envelope display of the slow attack AGC operating characteristics when activated with a $20 \mathrm{~dB}$ sine wave pulse. 


\section{CHAPTER V \\ CONCLUSIONS AND IMPLICATIONS}

\section{SUMMARY}

The focus of this investigation was directed toward a better understanding of the effects of hearing aid automatic gain control (AGC) on the intelligibility of speech. Specifically, the study compared a fast attack AGC circuit with a slow attack AGC, whereas all other variable parameters associated with $A G C$ amplifiers were held constant.

A hearing aid AGC amplifier was modified for this study to provide a fast attack time of 40 milliseconds (ms) and a slow attack time of $600 \mathrm{~ms}$. The release time was $650 \mathrm{~ms}$ for both attack circuits. Twenty-four normal hearing subjects (18-30 years old) listened to sixty pre-recorded PAL-8 sentences. Thirty sentences were modified by fast attack AGC and thirty by slow attack AGC. Each subject had a printed form which included four multiple-choice answers for each sentence. The most correct answer was to be underlined. In order to provide a sufficiently difficult task for normal hearing subjects a masking noise was dubbed onto the stimulus tape recording after the hearing aid AGC output was recorded at a $-4 \mathrm{~dB}$ signal-to-noise ratio.

The mean number of sentences answered incorrectly when heard through fast attack AGC was 8.25, and when heard through slow attack AGC the mean was 6.67 errors. 


\section{CONCLUSTONS}

The results of this investigation justify the following conclusions:

1. Differences of intelligibility between fast and slow attack AGC were statistically significant at the 0.05 level of confidence when conducted under the conditions of this study.

2. The slow attack time mode resulted in greater intelligibility of speech than the fast attack time mode.

3. The AGC attack times should be assessed with a typical speech signal as well as a pure tone signal. The possibility exists that the test stimulus duration may be inadequate to derive full benefit of the AGC. A speech discrimination task utilizing single word presentations is possibly too short in time duration to test AGC capabilities.

4. The PAL-8 sentence discrimination test is a satisfactory tool for hearing aid evaluation. The test should be a particularly well-suited tool if the hearing aid utilized AGC. Due to the vintage of the material (1944) and the population for which it was intended (military) some sentences may have to be edited because of a lack of knowledge of the subject. 


\section{IMPLICATIONS}

other considerations may be implied for future study as a result of the present study:

1. Conduct a study in which masking noise is introduced prior to AGC. This would provide information about AGC operation in circumstances more consistent with those found in everyday hearing aid usage.

2. The use of subjects with hearing pathologies would be important since, typically, hearing aid users do not have normal auditory acuity.

3. A variety of AGC attack times, other than $40 \mathrm{~ms}$ and $600 \mathrm{~ms}$, should be investigated.

4. The effect which a varying speech stimulus intensity has on speech intelligibility should be investigated. This condition would be more comparable to conversational speech than the closely regulated intensity used for this study.

In addition to the implications suggested above, the hearing aid evaluation (HAE) is an aspect of clinical practice in which knowledge derived from this study may be applied. Evaluation of hearing aids on patients should consider the aids' AGC characteristics and the duration of the speech discrimination stimulus utilized. Further, the clinician should consider the use of background noise as an integral portion of the $\mathrm{HAE}$ procedures. An understanding of AGC characteristics when subjected to speech signals should add further impetus to the consideration of background noise utilization for HAE's. 
Berger, Kenneth W. The Hearing Aid. Detroit: National Hearing Aid Soc., 1970. , and Joseph P. Millin. "Hearing Aids," Audiological Assessment, ed. Darrel E. Rose. Englewood Cliffs: Prentice Hall, 1971.

Black, W. L., and N. C. Norman. "Program-0perated Level-Governing Amplifier," Proc. Inst. Radio Engrs., XXIX (1941), 573-78.

Bruning, J. L., and B. L. Kintz. Computation Handbook of Statistics. Chicago: Illinois, Scott, Foresman \& Co., 1968.

Burchfield, S. B. "Perception of Amplitude Compressed Speech by Persons Exhibiting Loudness Recruitment." Unpublished Ph.D. Dissertation, Michigan State University, 1970.

Caraway, Betty J., and Raymond Carhart. "Influence of Compressor Action on Speech Intelligibility," J. Acou. Soc. Am., XLI (1967), $1424-33$.

Carver, W. F. "A Historical and Technical Review" (of hrg. aids), Handbook of Clinical Audiology, ed. Jack Katz. Baltimore: Williams \& Wilkins, 1972.

Clarkson, Quentin D. Associate Professor of Statistics in the School of Social Work, Portland State University.

Cook, E. G. "A Low Distortion Limiting Amplifier," Electronics, XII (1939), 38-40.

Davis, Hallowe11, and 0thers. Hearing Aids, an Experimental Study. Cambridge: Harvard Press, 1949.

Denes, Peter B., and Elliot N. Pinson. The Speech Chain. Bell Telephone Laboratories, 1963.

Edgardh, Bertil H. "The Use of Extreme Limitation for the Dynamic Equalization of Vowels and Consonants in Hearing Aids," Acta Otolaryng, XL (1951), 376-86.

Fletcher, H. Speech and Hearing in Communication. New York: D. Van Nostrand Co., 1953.

Frye, George A. Design Engineer and President, Frye Electronics, Beaverton, Oregon. 
Giolas, T. G., and A. Epstein. "Comparative Intelligibility Scores of Sentence Lists and Continuous Discourse," J.S.H.R., V (1962), 194-204.

Grason Stadler. 1701 Automatic Audiometer 0perating Manual. Cambridge, Mass., 1972 .

Hewitt, Chauncey. Zenith Hearing Instrument Corp., Los Angeles, Calif.

Hirsh, Ira J. The Measurement of Hearing. New York: McGraw-Hill Co., 1952.

Hudgins, C. V., and Others. "The Comparative Performance of an Experimental Hearing Aid and Two Commercial Instruments," J.Acou. Soc. Am., XX (1948), 241-55.

Jerger, James, C. Malmquist, and C. Speaks. "Comparison of Some Speech Intelligibility Tests in the Evaluation of Hearing Aid Performance," J.S.H.R., IX (1966a), 253-58.

Jerger, James, C. Speaks, and C. Malmquist. "Hearing-Aid Performance and Hearing-Aid Selection," J.S.H.R., IX (1966b), 136-49.

Karlin, J. F., and 0thers. Auditory Tests of the Ability to Hear Speech in Noise. Cambridge: Harvard Psycho Acoustic Laboratory, Harvard University, 1944.

Kretsinger, Elwood A., and Norton B. Young. "The Use of Fast Limiting to Improve the Intelligibility of Speech in Noise," $\mathrm{Sp}$. Monog., XXVII $(1960)$.

Licklider, J. C. R. "Basic Correlates of the Auditory Stimulus," Handbook of Experimental Psychology, ed. S. S. Stevens. New York: John Wiley \& Sons, 1951.

Lurch, E. Noman. Fundamentals of Electronics. New York: John Wiley \& Sons, 1971.

Lynn, George E. "Influence of Compression Amplification on the Perception of Speech by the Hearing Impaired." Unpublished Ph.D. dissertation, Northwestern University, 1962.

, and Raymond Carhart. "Influence of Attack and Release in Compression Amplification on Understanding of Speech by Hypoacoustics," J.S.H.R., XXVIII (1963), 124-40.

Parker, C. D. "The Effects of the Reduction of Short Time Fatigue on Speech Intelligibility for 'Perceptively' Deafened Individuals." Unpublished Ph.D. dissertation, State University of Iowa, 1953. 
Peterson, Thurman S. College Algebra. New York: Harper \& Bros., 1958.

Poliakiff, A. "Hearing Aid Design--Some Essential Qualities of a Good Instrument and Their Practical Realization," Wireless World, LVI (1950), 274-76.

Protter, Murray H., and Charles B. Morrey, Jr. College Calculus With Analytic Geometry. Palo Alto: Addison-Wesley, 1964.

Rintelman, W. R. "Effects of Amplitude Compression Upon Speech Perception," Scandinavian Aud., I (1972), 127-34.

Roberts, F. W., and R. C. Curtis. "Audio Automatic Volume Control Systems," J. Audio Engrg. Soc., I (1953), 310-16.

Rutherford, Charles R. "Instantaneous Speech Compressor," Electronics, XXX (1957), 168-69.

Sanders, Derek A. Aural Rehabilitation. Englewood Cliffs: PrenticeHall, 1971.

Sears, Francis Weston, and Mark W. Zemansky. College Physics. Reading, Mass.: Addison-Wesley, 1960.

Stuart, H. H., and H. S. Pollock. "Compression With Feedback," Electronics, XIII (1940), 19-21.

Yantis, Phillip A., J. P. Millis, and I. Shapiro. "Speech Discrimination in Sensori-Neural Hearing Loss: Two Experiments on the Role of Intensity," Speech and Hearing Res., IX (1966), 178-93. 
APPENDIX A

MASTER TAPE RECORDING SCRIPT AND SUBJECT TEST FORM 
Name

Age

Sex

Date

\begin{tabular}{rlllllll} 
V.A. & \multicolumn{3}{c}{ P.S.U. } & \multicolumn{4}{c}{ Subject No. } \\
& .25 & .5 & 1 & 2 & 4 & 8 \\
$\mathbf{R}$ & & & & & & \\
$\mathrm{L}$ & & & & & & \\
MCL & & & & & &
\end{tabular}

This is a test to see how well you can hear sentences spoken in noise. Some of the sentences are questions or commands. 0ther sentences are incomplete statements. After every sentence, you are to circle or underline the word or number which answers the question or command, or which completes the sentence. ALWAYS respond to each sentence. If you are not sure, GUESS. DO NOT LEAVE ANY SENTEENCES UNANSWERED.

Here are some practice sentences. Number one has already been correctly marked. ARE YOU READY?

1. Great Lakes

Atlantic

Pacific

Mediterranean

2. April

old

Idea

Seal
3. 12

1

9

7

4. Man

Mountain

Ant

Mouse

That is how the test will go. ALWAYS make a mark, even if you have to guess.

TURN THE PAGE OVER \& WAIT FOR TEST TO BEGIN. 
Form A Form C

1. Litter

Ladder

Letter

Latter

2. 12

4

8

3

3. Alaska

Ice

Eskimo

Mines

4. 4

$$
\begin{aligned}
& 4 \\
& 2 \\
& 8 \\
& 1
\end{aligned}
$$

5. 2

35

7

12

6. 0cean

Rotten

Food

Broken-down

7. Furnaces

Winter

Tickling

Spring

8. Leg

Body

Head

Foot

9. Kindness

Slow

Runners

Food

10. 10 A.M.

Lunch

Supper

11 P.M.
11. 7

Car

Umbrella

12. Hot

Summer

Thermometer

Stove

13. Soldier

Bully

Cold

Boxer

14. 6

No

11

15. Captain

Major

Minor

Corporal

16. August

october

November

Autumn

17. Sunday

Engl and

Washington

Rome

18. Silk

$\mathrm{Fish}$

Caterpillar

Worm-hole

19. $\begin{array}{llll}30 & 38 & 25 & 72\end{array}$

20. $\quad 10 \frac{1}{2}$

5

20

10
21. North-Pole Winter

Ice

Mines

22. Pipes

Fire

Windows

Leaves

23. Donuts

Soup

Alcohol

Wasp

24. Den

Sheep

Dog

Bark

25. Lifting

Burning

Traveling

Flying

26. No

White

Yes

Winter

27. Music

Tennis

Shooting

Loud Noise

28. Keyhole

Mattress

Mat

Floorwax

29. Hive

Bee

Cricket

Treasury

30. Blind

Glasses

Dark

Invisible 
Form B Form D

1. Round

Red

Sweet

Cider

2. Round

Stee 1

Rubber

Glass

3. Forks

Lassoes

Hooks

Food

4. Diamonds

Blood

Green

Sky

5. Ground

Stoves

Cellars

North-Pole

6. Gray

Sunny

Blue

Picnic

7. 13

17

Baby

2 . Weeks

8. Dwarf

Flower

5 cents

Mouse

9. Referee

First

Hurdler

Last

10. News

Press

Paper

Reporter
11. Swindle

Mist

Tadpole

Puppy

12. Yes

Mt. Everest

Drinking-water

No

13. Compass

Printing-press

Author

Feet

14. Gum

Gun

Bun

Bum

15. Skating

Keeping money

Fur coats

Getting married

16. Meals

Fire-engines

Mailman

Envelopes

17. Meals

Breakfast

Supper

Lunch

18. 4

75.

2

50

19. Diamonds

Lead

Expensive

Elephant

20. Evening

West

Red

Chair
21. Eating

Garden

Caterpillars

Fishing

22. Kitchen

Fishing

Beautiful

Library

23. Locomotive

Engineer

Tracks

Coach

24. Moving companies

Actors

Film

Canvas

25. Admiral King Popeye

General MacArthur

Greta Garbo

26. Grapes

Fruit

Sherry

Alcohol

27. Night

Beds

Rest

Meals

28. Giant

Mouse

Man

Dwarf

29. Texas

Platter

Lake Superior

Rhode Island

30. Yes

5

No

10 


\section{RECORDING SCRIPT AND ANSWERS FOR PAL-8 SENTENCE \\ SPEECH DISCRIMINATION TASK}

This is a test to see how well you can hear sentences spoken in noise. Some of the sentences are questions or commands. Other sentences are incomplete statements. After every sentence, you are to circle or underline the word or number which answers the question or command, or which completes the sentence. ALWAYS respond to each sentence. If you are not sure, guess. DO NOT LEAVE ANY SENTENCES UNANSWERED.

Here are some practice sentences. Number one has already been correctly marked. ARE YOU READY?

1. What is the ocean east of the United States?

Atlantic

2. Underline the month which comes before May.

Apri1

3. The sume of four plus three is:

7

4. The name of the thing is:

Mountain

That is how the test will go. Always make a mark, even if you have to guess.

TURN THE PAGE OVER AND WAIT FOR THE TEST TO BEGIN.

ARE YOU READY? Circle Form A (B, C, D)

1. Underline ladder.

Ladder

2. What is six times two?

12

3. The coldest land is:

Alaska

4. Which is smaller, six or two?

2

5. What is seven and five?

6. The thing which is salty is:

ocean

7. The cold weather ends in:

Spring 
8. Between the head and leg is the:

body

9. A mile-race has:

runners

10. Which meal is nearer midnight?

supper

11. The longest word of these four is:

umbrella

12. We measure heat with a:

thermometer

13. The man who fights with gloves is a:

boxer

14. Is eight more than three plus three?

yes

15. Underline the lowest of the ranks.

Corpora1

16. What month comes after September?

October

17. London is the name of a city in :

England

18. Name the cloth made by a worm.

silk

19. What is the number to the right of 38 ?

25

20. Half of ten is:

5

21. When it gets very cold, water becomes:

ice

22. Tobacco is smoked in:

pipes

23. You can get drunk from:

alcohol

24. A wolf is like a wild:

$\operatorname{dog}$

25. A train is used for:

traveling

26. Is milk the color of snow?

yes

27. A racket is used for playing:

tennis

28. What makes your feet slip?

floorwax

29. What insect does honey come from?

bee

30. A man who cannot see is:

blind 
31. The taste of a ripe apple is:

sweet

32. The tires on a car are made of:

rubber

33. You catch fish with:

hooks

34. Rubies are the same color as:

blood

35. Coal is burned in:

stoves

36. On a clear day the weather is:

sunny

37. Which of these numbers is nearest fourteen?

13

38. Underline the smallest sum of money.

5 cents

39. The winner of a race is:

first

40. On what material is a newspaper printed?

paper

41. Before it becomes a frog, it is called a:

tadpole

42. Is a hill larger than a mountain?

no

43. Books are printed on a:

printingpress

44. Underline the word "bun". bun

45. A rink is used for:

skating

46. You enclose letters in:

envelopes

47. Which meal do you eat at noon?

lunch

48. What is twice 2?

4

49. Which object sparkles the most?

diamonds

50. When does the sun set?

evening

51. A worm is used for:

fishing

52. A place with books is:

library

53. A train is driven by a;

engineer

54. Moving pictures are make by:

actors

55. Which of these is the name of a soldier? 
56. Name the fruit used to make wine.

grapes

57. When do people sleep?

night

58. What is the name of the smallest human?

dwarf

59. The name of a large state is :

Texas

60. Does five plus five make twenty-five?

no 
APPENDIX B

AMPLIFIER SCHEMATIC 


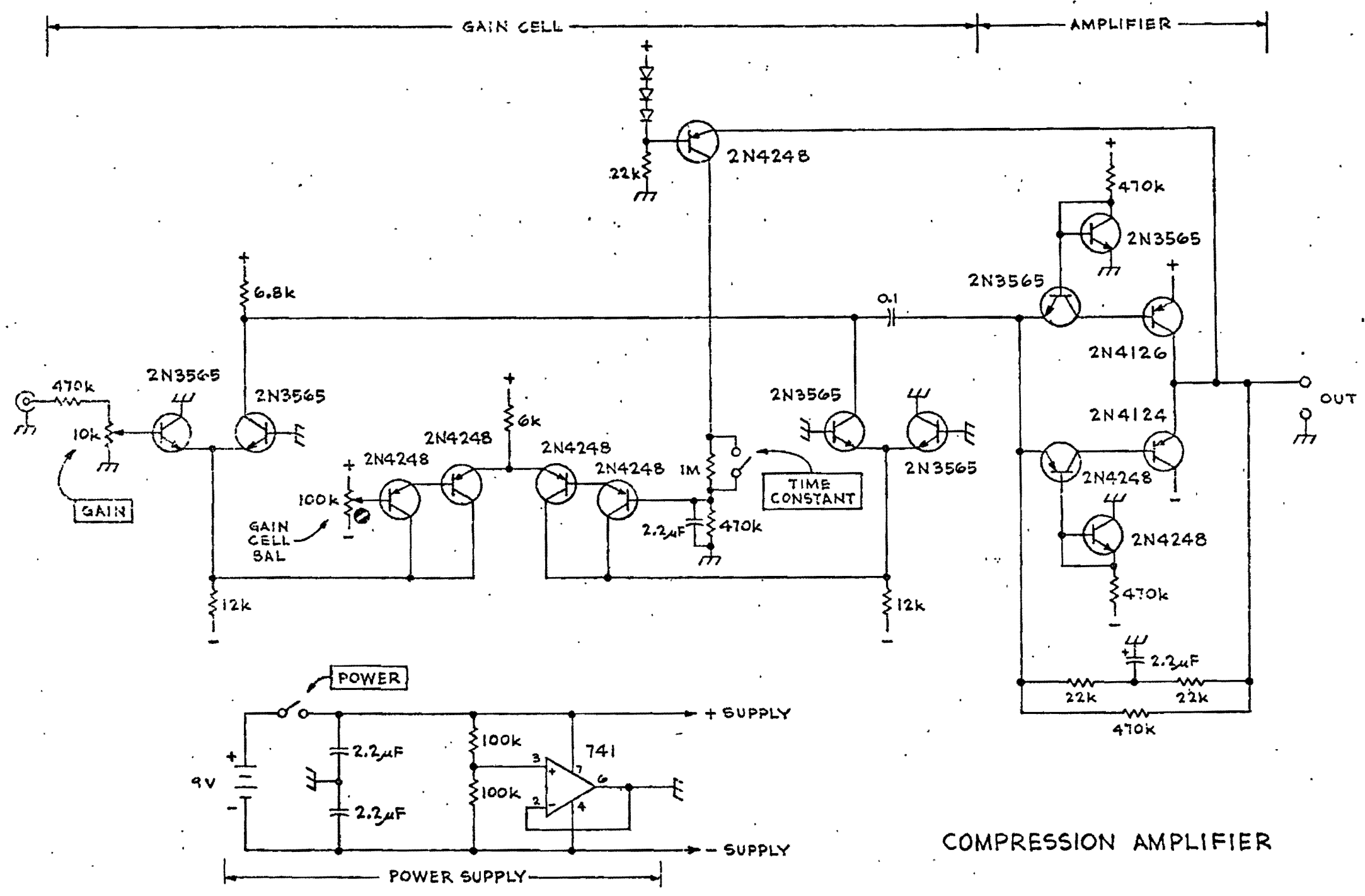


APPENDIX C

DATA ON AMPLIFIER CHARACTERISTICS 


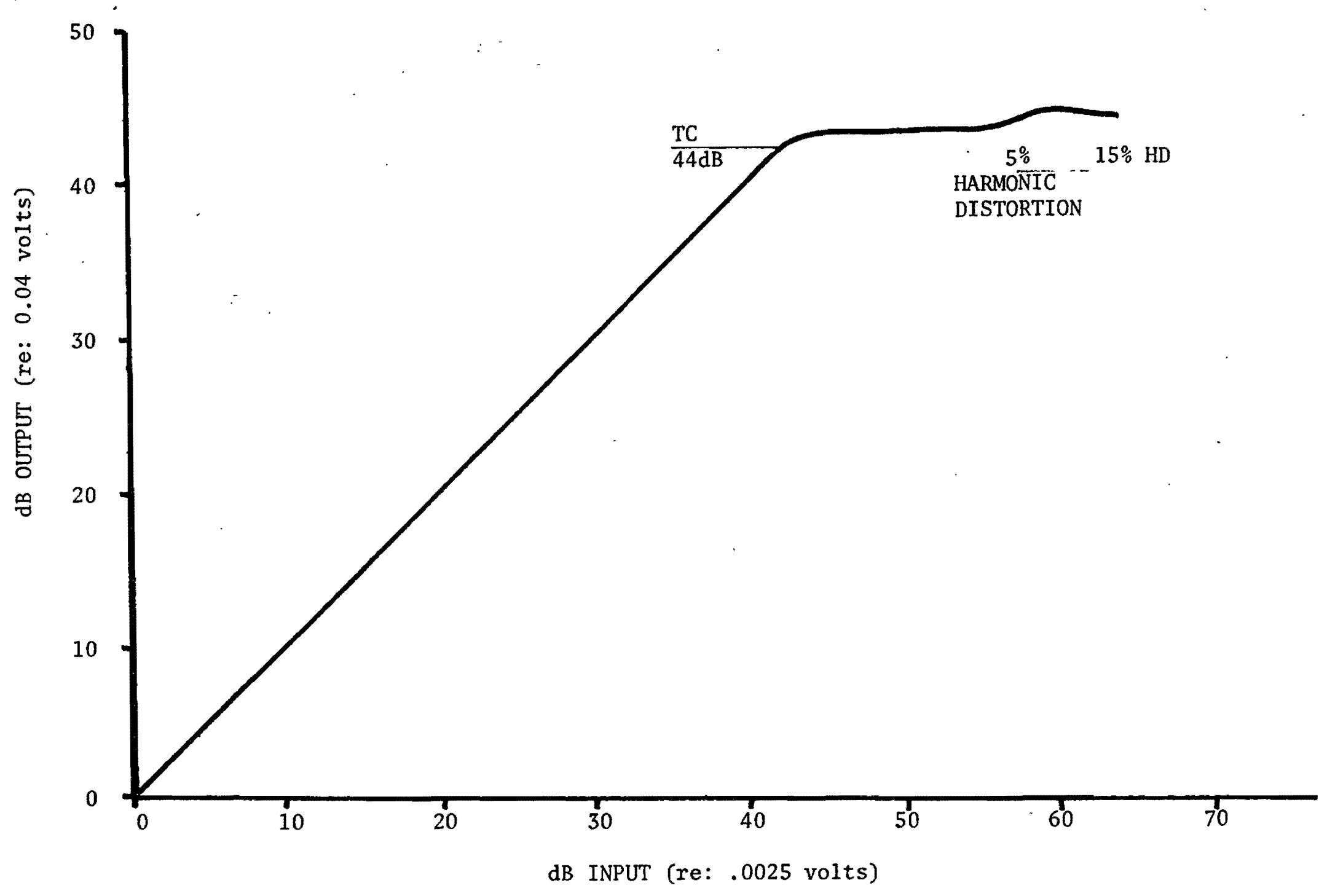

Gain Charateristics of Experimental AGC Amplifier 


\begin{tabular}{|c|c|c|c|c|}
\hline $\mathrm{dB}$ input & $\begin{array}{l}\text { volts } \\
\text { P-P } \\
\text { input }\end{array}$ & $\begin{array}{l}\text { SLOW } \\
\text { volts } \\
\text { P-P } \\
\text { output }\end{array}$ & $\begin{array}{l}\text { FAST } \\
\text { volts } \\
\text { P-P } \\
\text { output }\end{array}$ & dB output \\
\hline 0 & .0025 & .04 & .042 & 0 \\
\hline 10 & .0085 & .130 & .135 & 10 \\
\hline 20 & .027 & .43 & .42 & 20 \\
\hline 30 & .085 & 1.33 & 1.35 & 30 \\
\hline 40 & .27 & 4.3 & 4.3 & 40 \\
\hline 41 & .3 & 4.8 & 4.8 & 41 \\
\hline 42 & .34 & 5.3 & 5.4 & 42 \\
\hline 43 & .38 & 6.0 & 6.0 & 43 \\
\hline 44 & .43 & 6.5 & 6.4 & 43.5 (TC) \\
\hline 45 & .48 & 6.5 & 6.5 & 43.6 \\
\hline 46 & .54 & 6.5 & 6.5 & 43.6 \\
\hline 47 & .61 & 6.5 & 6.5 & 43.6 \\
\hline 48 & .68 & 6.5 & 6.5 & 43.6 \\
\hline 49 & .76 & 6.5 & 6.5 & 43.6 \\
\hline 50 & .85 & 6.5 & 6.5 & 43.6 \\
\hline 51 & .96 & 6.5 & 6.5 & 43.6 \\
\hline 52 & 1.08 & 6.5 & 6.5 & 43.6 \\
\hline 53 & 1.21 & 6.5 & 6.5 & 43.6 \\
\hline 54 & 1.35 & 6.6 & 6.5 & 43.7 \\
\hline 55 & 1.52 & 6.6 & 6.6 & 43.7 \\
\hline 56 & 1.70 & 6.6 & 6.6 & 43.7 \\
\hline 57 & 1.91 & 6.7 & 6.7 & 43.8 \\
\hline 58 & 2.14 & 6.8 & 6.8 & 44.0 \\
\hline 59 & 2.41 & 7.1 & 7.0 & 44.25 \\
\hline 60 & 2.70 & 7.3 & 7.3 & 44.6 \\
\hline
\end{tabular}


APPENDIX D

RAW DATA 


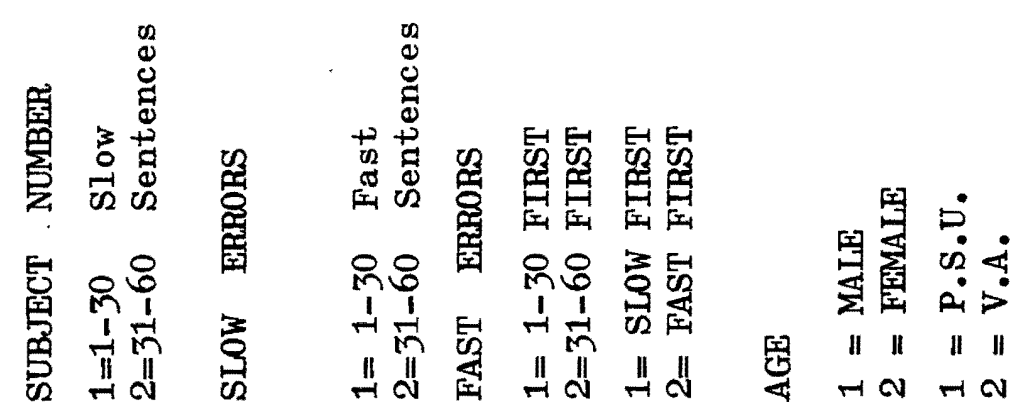

$\begin{array}{rrrrrrrrrrr}\text { FORM A } & 1 & 1 & 7 & 2 & 9 & 1 & 1 & 30 & 1 & 2 \\ & 5 & 1 & 10 & 2 & 10 & 1 & 1 & 30 & 2 & 1 \\ & 9 & 1 & 9 & 2 & 5 & 1 & 1 & 23 & 2 & 1 \\ & 13 & 1 & 12 & 2 & 8 & 1 & 1 & 28 & 2 & 2 \\ & 17 & 1 & 8 & 2 & 10 & 1 & 1 & 24 & 1 & 1 \\ & 21 & 1 & 6 & 2 & 11 & 1 & 1 & 26 & 1 & 1\end{array}$

$\begin{array}{rrrrrrrrrrr}\text { FORM B } & 2 & 1 & 4 & 2 & 7 & 2 & 2 & 23 & 2 & 1 \\ & 6 & 1 & 4 & 2 & 11 & 2 & 2 & 28 & 1 & 1 \\ & 10 & 1 & 14 & 2 & 9 & 2 & 2 & 19 & 2 & 2 \\ & 14 & 1 & 7 & 2 & 8 & 2 & 2 & 27 & 2 & 1 \\ & 18 & 1 & 6 & 2 & 4 & 2 & 2 & 25 & 1 & 2 \\ & 22 & 1 & 5 & 2 & 8 & 2 & 2 & 21 & 2 & 2\end{array}$

$\begin{array}{rrrrrrrrrrr}\text { FORM C } & 3 & 2 & 7 & 1 & 13 & 1 & 2 & 30 & 2 & 2 \\ & 7 & 2 & 9 & 1 & 13 & 1 & 2 & 21 & 1 & 1 \\ & 11 & 2 & 3 & 1 & 3 & 1 & 2 & 22 & 1 & 1 \\ & 15 & 2 & 6 & 1 & 5 & 1 & 2 & 22 & 2 & 1 \\ & 19 & 2 & 4 & 1 & 8 & 1 & 2 & 27 & 1 & 1 \\ & 23 & 2 & 5 & 1 & 9 & 1 & 2 & 25 & 2 & 2\end{array}$

$\begin{array}{rrrrrrrrrrr}\text { FORM D } & 4 & 2 & 10 & 1 & 6 & 2 & 1 & 28 & 2 & 1 \\ & 8 & 2 & 4 & 1 & 5 & 2 & 1 & 23 & 1 & 2 \\ & 12 & 2 & 6 & 1 & 9 & 2 & 1 & 30 & 2 & 2 \\ & 16 & 2 & 7 & 1 & 13 & 2 & 1 & 21 & 2 & 1 \\ & 20 & 2 & 3 & 1 & 8 & 2 & 1 & 24 & 1 & 2 \\ & 24 & 2 & 4 & 1 & 6 & 2 & 1 & 26 & 2 & 1\end{array}$


THIS THESIS WAS TYPED BY LESLIE GRUEGER. 